\title{
Aerothermodynamic Optimization of Hypersonic Vehicle TPS Design by a POD/RSM-Based Approach
}

\author{
P.C. Chen ${ }^{1}$, D.D. Liu ${ }^{2}$, K.T. Chang \\ L. Tang ${ }^{3}$, X.W. Gao ${ }^{3}$ \\ ZONA Technology, Inc. \\ Scottsdale, AZ \\ info@zonatech.com, \\ Tel 480-945-9988
}

\author{
Amarshi Bhungalia ${ }^{4}$ \\ Phil Beran ${ }^{5}$ \\ AFRL/VA, WPAFB, OH \\ Amarshi.Bhungalia@wpafb.af.mil \\ Tel: 937-255-8335
}

\author{
Wei Shyy ${ }^{6}$ \\ Dept. Aerospace Engineering \\ University of Michigan \\ Ann Arbor,MI \\ weishyy@umich.edu \\ Tel: 734-936-0102
}

This paper presents an automated 3D design procedure called TPSOPT, the thermal protection system (TPS) optimization for hypersonic vehicle heatshield designs. TPSOPT is imbedded in a hypersonic aerodynamics and aerothermodynamics for TPS (HYAAT) system. Hence the essential modules in HYAAT including the aerodynamics/aerothermodynamics (AA), the TPS sizing, and an AA submodule, as an expedient CFD aerodynamic tool, called proper orthogonal decomposition (POD)/response surface method (RSM) are first reviewed. Aerodynamic and aerothermodynamic data are provided through the POD/RSM-based CFD methodology, thereby it can expediently furnish the surface skin friction/heat transfer coefficients per a given trajectory. The TPS sizing objective is to minimize the TPS weight while satisfying the structural constraints and the thermal protection requirement of a combined RLV/TPS design. With a complex variable differentiator for sensitivity and an optimizer ASTROS, TPSOPT optimizes the TPS thickness distribution by assigned shape functions. Here the number of design variables can be significantly reduced since the coefficients of those shaped functions are determined rather than the thickness variable itself. A modeled X34 is selected as a case-studied example to demonstrate the TPSOPT methodology. Typical CPU time for each POD-based CFD solution requires only a few second on a PC. TPSOPT for a TPS design solution requires approximately 4 hours per trajectory.

\section{Introduction}

For hypersonics and space access, the National Aerospace Initiative (NAI) goals are: (i) Hypersonics flight demonstrate increasing Mach number capability each year, reaching Mach 12 by 2012; (ii) Space Access - demonstrate technologies that will drastically increase space access and reliability while decreasing cost. In response to these initiatives, needed technologies were identified by NASA/DoD, to support safe but cost effective launch and recoverable systems. To this end, integrated software development in aerothermodynamics, aerothermoelasticity, thermal protection systems (TPS) and multidisciplinary design optimization (MDO) for RLV in extreme environment are among the urgent enabling technologies.

With ongoing supports of several government agencies, together with our in-house R\&D resources, ZONA has been gradually building up a Hypersonic Aerodynamics/Aerothermodynamics for TPS (HYAAT) software system whose capability now ranges from RLV/TPS to space-access vehicle for their design/analysis. The HYAAT system was initiated by a continuing AFRL contractual support [1]; its progress and development has been reported in $[2,3,4]$. The objective in this paper is to describe the TPS design for aerospace vehicles using a POD/RSM-based aerodynamic method. To do so, it is important to begin with our recent advances of the HYAAT system, because the POD/RSM methodology is imbedded in one of its essential modules. The HYAAT system essentially consists of 4 major modules (see Figs. 1,2). These include: the Aerodynamics/Aerothermodynamics (AA) module, the TPS sizing module, the ASTROS module (automated structural optimization systems, Fig 3) [5,6,7], and the Trajectory module. Here we will confine our reporting only to the progress of the first two modules, since they are the essential pieces in the HYAAT system wherein we focus on our present R\&D efforts.

AIAA-2006-0777 presented at the 44th AIAA Aerospace Sciences Meeting and Exhibit
1. Vice President, Member AIAA
2. President, Fellow AIAA
3. Technical Staff
4. Project Monitor, Associate Fellow AIAA
5. Principal Senior Engineer Associate Fellow AIAA
6. Kelley Johnson Professor and Chair, Fellow AIAA 
The aerodynamics/aerothermodynamics module has been generalized from a lower-hierarchy panel method approach, ZONAIR [8,9] to including a high-level flow solver CFL3D [12] coupled with a Proper Orthogonal Decomposition (POD) procedure $[14,15]$. The TPS sizing module using the NASA supported MINIVER [10] has been improved to add-in an automated optimization scheme for TPS weight minimization while satisfying all aerothermal and structural constraints. In what follows we will go into the specifics of these two improved modules. Whenever appropriate, applications to basic configurations and several hypersonic flight vehicles will be presented to demonstrate the validity of the HYAAT methodology.

\section{The Aerodynamics/Aerothermodynamics Module}

The earlier AA module of HYAAT presented in Fig 1 include an Aerodynamic module ZONAIR which is unified in subsonic-supersonic-hypersonic flight regimes as an aerodynamics module for rapid engineering design/analysis. ZONAIR is coupled with the Aerothermodynamic module using a modified SHABP [11] for aerodynamic drag and thermal/heat rate evaluations. Subsequently, the improved AA module in Fig 2 is to replace ZONAIR in the earlier AA module with a NASA supported high-level CFD method, CFL3D, to account for aerodynamic nonlinearity arising from the extreme flight environment. There CFL3D is coupled with the POD method in conjunction of the response surface method (RSM) technique for rapid CFD solution and generation retrieval. Currently, these two AA modules have been merged into one whereby the low-level ZONAIR and/or the high-level CFD/POD can be a user option. The future plan is to construct a grand AA module with the current AA module, ZONAIR and CFD/POD, integrated into a Computational Aerodynamic/Aerothermodynamics Software Toolbox (CAAST). This plan will be described in the last section.

\section{A. ZONAIR -- the Low-Level Computational AA Module}

ZONAIR is an expedient high-fidelity 3D panel code for rapid design/analysis of very complex wings/bodies. It is an ideal method for rapid conceptual design, for it is a compromise between the computational expediency and solution accuracy among all the methods concerned (see Fig 4). More importantly, it covers the unified subsonic, sonic, supersonic and hypersonic flight regimes. Given flight conditions, it efficiently generates aerodynamic pressures/forces/moments for rigid/elastic bodies thus creates aerodynamic and loads databases for 6DOF simulation and critical loads identification. ZONAIR is formulated based on the unstructured surface panel scheme that is compatible to the finite element methods. This enables the direct adoption of off-the-shelf finite element pre- and post-processors such as PATRAN, I-DEAS, FEMAP, etc. for ZONAIR panel model generation. The specific capabilities of ZONAIR are also clearly stated in Fig 4.

ZONAIR consists of many submodules for various disciplines that include (1) AIC matrix generation module, (2) 3-D spline module, (3) Trim module, (4) Aeroheating module, (5) Vortex roll-up module, and (6) Aerodynamic stability derivative module. The interrelationship of ZONAIR with other engineering software systems such as the pre-processor, structural finite element method (FEM), Computational Fluid Dynamics (CFD) method, six degree-of-freedom (6 d.o.f.) and critical loads identification is depicted in Fig 5.

ZONAIR has been under continuous development by ZONA throughout the last decade. Its current version has proven capability accounting for multi-body interference, ground interference, wave reflection and store-separation, aerodynamics in hypersonic/supersonic as well as subsonic flow domains (Fig. 5). By comparison, ZONAIR is clearly the best choice as an expedient and versatile aerodynamic methodology. In what follows, we present the results of several hypersonic aerodynamics/aerothermodynamics applications based on ZONAIR and CFL3D [12]. These include: CKEM (Compact Kinetic Energy Missile) at $M=6.0, \alpha=2^{\circ} ; 15^{\circ}$ Blunt Cone at $M=10.6$ and $\alpha=5^{\circ} ; \mathrm{X}$ 34 at $\mathrm{M}=6.0, \alpha=9^{\circ}$ and altitude $=183 \mathrm{Kft}($ Figs 6,7,8). 


\section{B. POD-Based CFD -- the High-Level Computational AA Module}

A high-level CFD method is needed to improve the AA module capability to account for the flow nonlinearity in hypersonic flow regime and under extreme environments while performing space access activities.

We employed CFL3D as the primary CFD method for the improved AA module. Supported by NASA Langley, CFL3D is a Euler/thin-layer RANS code including various turbulence models, [12]. CFL3D is coupled with LATCH [13] for thermal/heat rate evaluation.

Normally, the computational efficiency of a high-level CFD methods such as CFL3D would require excessive computing time for analysis and design. Although computationally efficient, the lower-level aerodynamic methods such as ZONAIR are inadequate to accurately predict blunted-nose and lee-side aerodynamics particularly under high angles of attack and in the hypersonic flight regime. This prompts us to utilize a Proper Orthogonal Decomposition (POD) technique in conjunction with a response surface method (RSM) and apply it to the high-level CFD solver, such as CFL3D, for rapid generation of the computed aerodynamic and aerothermodynamic results. (Figs 9,10,11) Indeed, it turns out that the $\mathrm{POD} / \mathrm{RSM}$ method is a remarkable tool in offering fast CFD solutions while meeting the other design/analysis computational requirements. [14,15]

Simply put, POD/RSM is a procedure that massively computes and compiles CFD/POD solutions in an off-line manner, then it will retrieves and regenerates new trained CFD solutions effectively in an on-line manner. The global architecture of the proposed POD/RSM-based aerodynamic analysis approach is presented in Figure 9. There are three essential blocks: CFD/Euler computations at a series of the selected training points for creation of an extensive CFD solution database, POD of the CFD solution matrix for extraction of the principal basis functions from the CFD solutions, RSM to train the resulting reducedorder model and generate a hypersonic aerodynamic module for TPS/RLV structural design and optimization.

The POD/RSM procedure can be demonstrated through the present X-34 case studied. An extensive CFD solution database for X-34 is first created through massive off-line computation. The "snapshot" approach of Proper Orthogonal Decomposition (POD) technique is applied to facilitate reduced-order modeling of hypersonic aerothermodynamics by selecting two physical parameters, namely the angle of attack and the freestream Mach number. The reduced-order scheme of POD is to minimize the computed POD mode solutions, which is used to construct the RSM solution surfaces. Therein, the scalar coefficients will be determined by the Response Surface Method (RSM) in conjunction with a Neural Networks (NN) training scheme. (Figs 10,11,12) In the present X-34 case, only first three POD modes are found to sufficiently represent the targeted solution through CFD solution reconstruction via $\mathrm{POD} / \mathrm{RSM}$ over the entire range of angles of attack. Note that POD/RSM solutions can recover the direct CFD solution essentially within 5\% of error, by using just 10 POD modes. Study of the POD solution convergence (Fig 13,14) suggests a continuous variation of solution in the design space.

For a complex geometry of X-34, POD/RSM is found to provide accurate CFD solutions with the lee-side aerodynamics resulted form stringent high angle of attack conditions. Figs. 15 and 16 show POD/RSM solutions versus direct CFD solutions for X-34 under two set of selected flow conditions at Mach 2.0 and 10.0. Further, each POD/RSM solution performed on-line requires only a few second computing time on a PC. Thus, the POD/RSM solution method in the AA module is equally computationally efficient to, if not more efficient than, the low-level panel methods; it can also achieve same order of solution accuracy as that of the direct high-level CFD methods. 


\section{The TPS Sizing Module}

To demonstrate the developed thermal protection system (TPS) sizing module, we adopted the X-34 configuration and trajectories that were provided by Orbital Sciences [16] and NASA Langley [17] (Figs 17,18). The ZONA X-34 Structural/FEM model (and its stress plot at trim) is shown in Fig 19. This modeled X-34 is used throughout for our cases studied of TPS sizing module development. In what follows, we will present the evolution in our TPS sizing modules. This amounts to using different generations of AA modules, i.e. ZONAIR and CFD/POD methods. The current AA module works well with the new TPS module with an optimization scheme, called TPSOPT. The TPS design process using TPSOPT can be seen from Figs 26-34.

\section{A. Elementary TPS Sizing -- using ZONAIR}

The TPS sizing objective is to minimize the TPS weight while satisfying structural constraints and the thermal protection requirement of the RLV/TPS structures. The developed TPS sizing procedure can be demonstrated by a constructed prototypical TPS/AFRSI (Advanced Flexible Reusable Surface Insulation) model [18] (Figs 20). Here we adopt the complex variable differentiation technique [3] to derive the sensitivity of the NASA aerothermal code MINIVER [10] for TPS sizing/optimization procedure (Fig 21). Minimum thicknesses for all six layers of the selected TPS are posed as a part of the constraints (lower bounds). The initial temperature is $100^{\circ} \mathrm{F}$ and the maximum temperature constraint at the $6^{\text {th }}$ layer (bottom) is $300^{\circ} \mathrm{F}$ (Note that each layer has its own maximum temperature constraint posed as well). The complex variable differentiation sensitivity is shown to be superior to that obtained by conventional finite difference method for temperature changes of layer 6 due to a thickness change in layer 3 (Fig 22). With the computed MINIVER sensitivity, TPS optimization can then be carried out by ASTROS; the procedure is shown in Fig 23. The final outputs in terms of final (optimized) thickness, temperature and weight for each layer are listed in Fig 24.

\section{B. Automated TPS Sizing -- POD/RSM-based TPSOPT}

Presently, an automated optimization procedure for TPS weight sizing has been developed using ASTROS optimizer operated on MINIVER using the complex-variable-differentiation derived sensitivity. Specifically, the TPS module employs the automated optimization technique of ASTROS for the minimum weight design of the TPS while subjected to the temperature constraints at each TPS layer. The sensitivities of the weight and constraints with respect to the change of design variables are obtained using the complex variable differentiation technique. The whole surface of the vehicle can be divided into several patches, within each patch a different TPS structural design concept and material can be selected to ensure the smoothness of the thickness distribution of the TPS. TPS optimizer (TPSOPT) assumes that the thickness distribution is represented by several shape functions. Thus the design variables of the optimization are the coefficients of those shaped functions, not the thickness of the TPS. This then significantly reduces the number of the design variables. (Figs. 25-30) Meanwhile supplied aerodynamic and aerothermodynamic data are provided through the proper orthogonal composition (POD)/response surface method (RSM)-based CFD methodology. Thus TPSOPT can expediently furnish the time history of the surface heat transfer coefficients due to a given trajectory.

For demonstration, the TPSOPT is applied to the full configuration of X-34 for the TPS design covering the lee-side and wind-side surfaces (Figs 31, 32). In Fig. 33, it is seen that final (optimized) thickness of TPS in the nose region (patches 1 and 2) is about one order of magnitude thinner than its initial thickness. The optimized total TPS weight is found to be reduced by $22 \%$ terminated after the $20^{\text {th }}$ design cycle, while satisfying all TPS temperature constraints (Fig 34).

\section{CAAST Pyramid}

To serve as an improved tool for the TPS design, our future plan is to extend the current AA module to a grand AA module, called Computational Aerodynamic/Aerothermodynamics Software Toolbox (CAAST). The pyramid structure showing CAAST (Fig 35) consists of two aerodynamic approaches 
(layers): the Gas-kinetics and the Continuum. The gas-kinetic approach (layer) consists of the microscopic solvers of DSMC (Direct Simulation Monte Carlo) and the Boltzmann/BGK solver [19]. The continuum approach (layer) contains the macroscopic solvers ranging from RANS (Reynolds averaged Navier-Stokes) to potential flow including CFL3D [12] and ZONAIR [8,9]. The left-hand face of the pyramid lists the aerodynamic methods whereas the right-hand face the aerothermodynamic methods. The two arrows along the slopes indicate the user's preference for computational efficiency or flow physics. For example, for conceptual design of a RLV, one needs to apply ZONAIR at the bottom layer. For accuracy in detailed analysis in heat rate prediction, one needs to examine the solutions due to RANS/LAURA [20] and CFD/BGK [21] in the upper layer. Further the CAAST pyramid is supported by four kinds of mesh/grid generations: surface panels, structured grids, unstructured grids and a grid free scheme [22]. Note that one can apply POD/RSM to any level of the CFD methods, continuum or gaskinetics.

\section{Conclusions}

On the Aerodynamic/Aerothermodynamic Modules of the HYAAT system

- ZONAIR is a panel method, but unified in subsonic-supersonic-hypersonic flight regime It is an effective aerodynamics module for rapid engineering design/analysis.

- The current AA module is to merge ZONAIR with a POD/RSM based CFD (CFL3D) accounting for rapid evaluation of aerodynamic nonlinearity and aerothermodynamics arising from the extreme hypersonic flight environment.

- It is this AA module that will supply the needed AA data for subsequent TPSOPT design.

- Our future plan is to construct a grand AA module by extending the current AA module to include gaskinetics CFD in a Computational Aerodynamic/ Aerothermodynamics Software Toolbox (CAAST).

On the TPSOPT Module of the HYAAT system

- The most time-consuming part of the TPSOPT is the generation of the aerodynamic database. However CFD solutions can be massively generated offline, and the newly trained solutions can be expediently generated on-line by the POD/RSM methodology. Each POD/RSM solution performed on-line requires only a few seconds of computing time on a PC.

- The CPU time of the TPSOPT is approximately 4 hours per trajectory and given flight conditions.

- An optimal TPS design can be rapidly generated by using TPSOPT provided that a built-in TPS material database is furnished and TPS structural design requirements specified.

- TPSOPT can generate graphic files by using commercial graphic software such as Tecplot, FEMAP and PATRAN. Thus post-processing of TPSOPT is very user friendly.

\section{Acknowledgement}

This work was performed under the support of the AFRL/SBIR Phase II contract (F33615-02-C-3213) entitled "Integrated Hypersonic Aerothermoelastic Methodology for TAV/TPS Structural Design and Optimization". The ZONA authors thank the technical support in Phase I rendered by: Dr. Jeffery Zweber; Mr. David Adamczak of AFRL/VASD (AEROHEAT), and that of Dr. William Wood and Dr. Steven Alter (X-34 Data and Grid Organization); Ms. Katheryn Wurster (MINIVER) of NASA-LaRC; Dr. Christ Riley of CFDesign (LATCH) and Dr. Harry Fuhrmann of Orbital/OSC (X-34 and Data release), during the performance of the Phase I contractual development.

\section{References}

[1] Liu, D.D., Chen, P.C., Tang, L., Chang, K.T., Chemaly, A., and Kamhawi, H., "Integrated Hypersonic Aerothermoelastic Methodology for Transatmospheric Vehicle (TAV)/Thermal Protection System (TPS) Structural Design and Optimization,” AFRL-VA-WP-TR-2002-3047, 2002. 
[2] Liu, D.D., Chen, P.C., Tang, L., Chang, K.T., "Expedient Hypersonic Aerothermodynamics Methodology for RLV/TPS Design," AIAA paper 2002-5129, $11^{\text {th }}$ AIAA/AAAF International Conference: Space Planes and Hypersonic Systems and Technologies, Sep, 2002, Orleans, France.

[3] Chen, P.C., Liu, D.D., Tang, L., Chang, K.T., "Hypersonic Aerothermodynamics/Aerothermoelastics Methodology for RLV/TPS Design and Analysis," AIAA paper 2003-0897, $41^{\text {st }}$ AIAA Aerospace Sciences Meeting, Jan, 2003, Reno, Nevada.

[4] Chen, P.C., Liu, D.D., Tang, L., Chang, K.T., Gao, X.W., "Hypersonic Aerothermodynamics using ZONAIR for RLV/TPS Design and Analysis," Thermal and Fluids Analysis Workshop (TFAWS) 2003, Aug, 2003, ODU center, Hampton, Virginia.

[5] Johnson, E.H. and Venkayya V.B., "Automated Structural Optimization System (ASTROS), Theoretical, User's, Application's, Programmer's Manual,” AFWAL-TR-88-3028, Vol. I-IV, Dec. 1998.

[6] Chen, P.C., Liu, D.D., Sarhaddi, D., Striz, A.G., Neill, D.J., and Karpel, M., "Enhancement of the Aeroservoelastic Capability in ASTROS," STTR Phase I Final Report, WL-TR-96-3119, Sep. 1996.

[7] Chen, P.C., Sarhaddi, D., and Liu, D.D., "Development of the Aerodynamic/Aeroservoelastic Modules in ASTROS," ZAERO User's/Programmer's/Applications/ Theoretical Manuals, AFRL-VA-WP-TR-19993049/3050/3051/3052, Feb. 1999.

[8] Chen, P.C. and Liu, D.D. "Unified Hypersonic/Supersonic Panel Method for Aeroelastic Applications to Arbitrary Bodies," Journal of Aircraft, Vol. 39, No. 3, May-June 2002.

[9] Chen, P.C. and Liu, D.D., "ZONAIR: A Finite-Element Based Aerodynamic/Loads System Using a Unified High-Order Sub/Super/Hypersonic Panel Methodology," Presented at Aerospace Flutter and Dynamics Council, May 8-10, 2002, Sedona, AZ.

[10] Engel, C.D., and Schmitz, C.P., "MINIVER Upgrade for the AVID System", Vol. 3, "EXITS User's and Input Guide," NASA CR-172214, Aug. 1983.

[11] Burns, K.A., Deters, K.J., Haley, C.P., Kihlken, T.A., "Viscous Effects on Complex Configurations." WLTR-95-3059, 1995

[12] Krist, S.L., Biedron, R.T. and Rumsey, C.L., “CFL3D User' Manual Version 5.0,” NASA Langley Research Center, Hampton, VA, 1997.

[13] Hamilton, H., "Users Manual for the Langley Approximate Three-Dimensional Convectivity Heating (LATCH) Code," NASA Unpublished Technical Memorandum, June 2001.

[14] Tang, L, Chen, P.C., Liu, D.D., Gao, X., Shyy, W., Utturkar, Y., Zhang, B.N., Beran, P., and Bhungalia, A., "POD/RSM-Based S/Hypersonic Aerodynamic Module for TPS/RLV Structural Design and Optimization: X34 Case Study," AIAA Paper 2005-0839, 43 ${ }^{\text {rd }}$ Aerospace Sciences Meeting and Exhibit, Reno, NV, 10-13 January 2005.

[15] Vaidyanathan, R., Papila, N., Shyy, W., Tucker, P.K., Griffin, L. W., Fitz-Coy, N. and Haftka, R.T, "Neural Network-Based and Response Surface-Based Optimization Strategies for Rocket Engine Component Design," AIAA-2000-4480.

[16] Freemanm D.C., Jr., Talay, T.A., and Austin, R.E., "Reusable Launch Vehicle Technology Program." IAF96V.4.01, Oct. 1996.

[17] Wurster, K.E., Riley, C.J., and Zoby, E.V., "Engineering Aerothermal Analysis for X-34 Thermal Protection System Design," Journal of Spacecraft and Rockets, Vol. 36, No. 2, 1999, pp. 216-228.

[18] Myers, D.E., Martin, C.J. and Blosser, M.L., "Parametric Weight Comparison of Advanced Metallic, Ceramic Tile, and Ceramic Blanket Thermal Protection Systems," NASA TM 2000-210289.

[19] Bhatnagar, P.L., Gross, E.P., and Krook, M., "A Model for Collision Processes in Gases. I. Small Amplitude Processes in Charged and Neutral One-Component Systems," Physical Review, Vol. 94 (1954), pp.511.

[20] Cheatwood, F.M., Gnoffo, P.A., "User's Manual for the Langley Aerothermodynamic Upwind Relaxation Algorithm (LAURA)," NASA-TM-4674, April 1996.

[21] Tang, L., and Xu, K., "Unified Gas-Kinetic Computational Algorithm for Continuum and Rarefied Flows," AIAA-2004-1179, 2004.

[22] Hui, W.H., and Tang, L., "A Unified Coordinates Approach to Computational Fluid Dynamics," AIAA-20034239, 2003. 


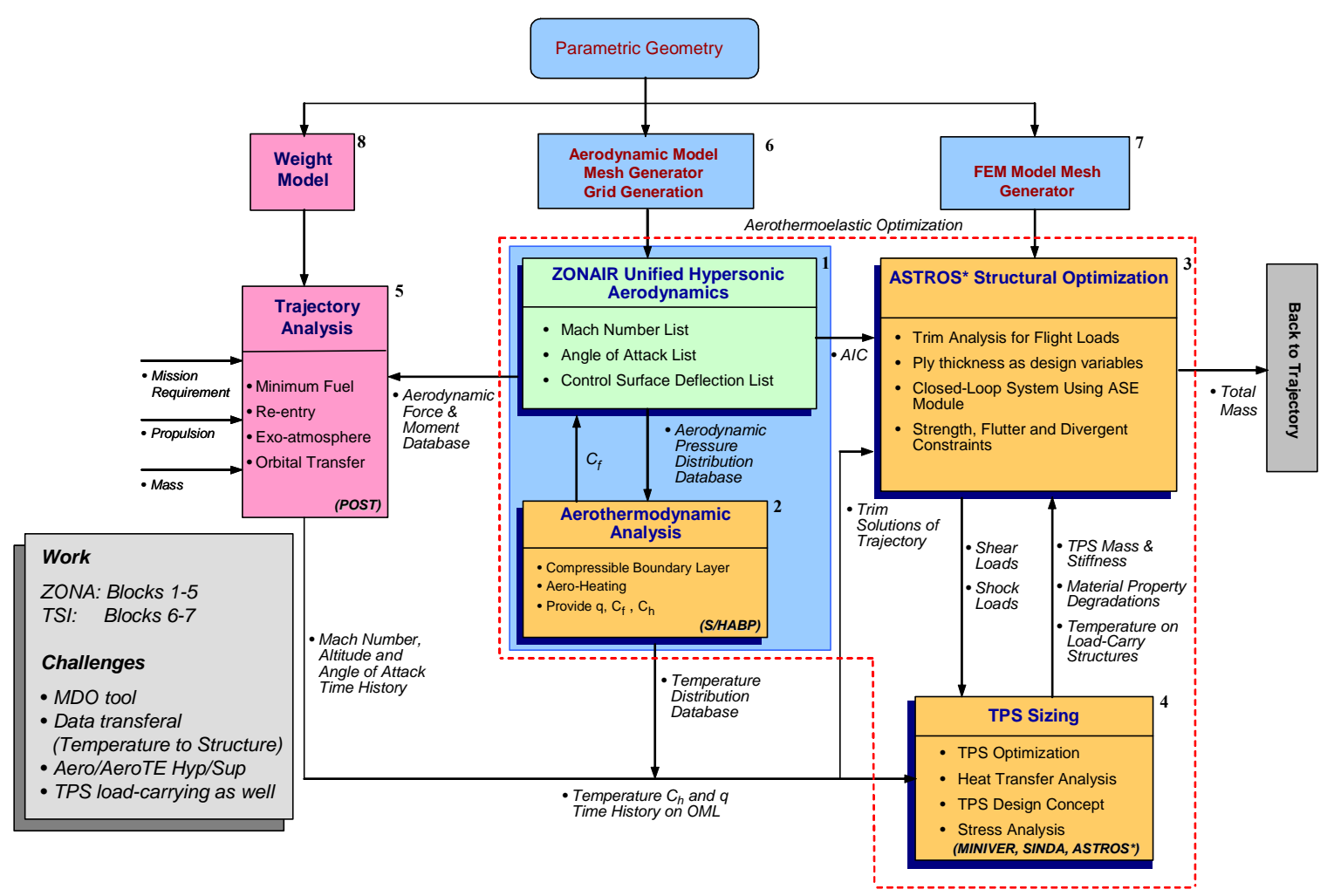

Figure 1. ZONAIR in the HYAAT software system

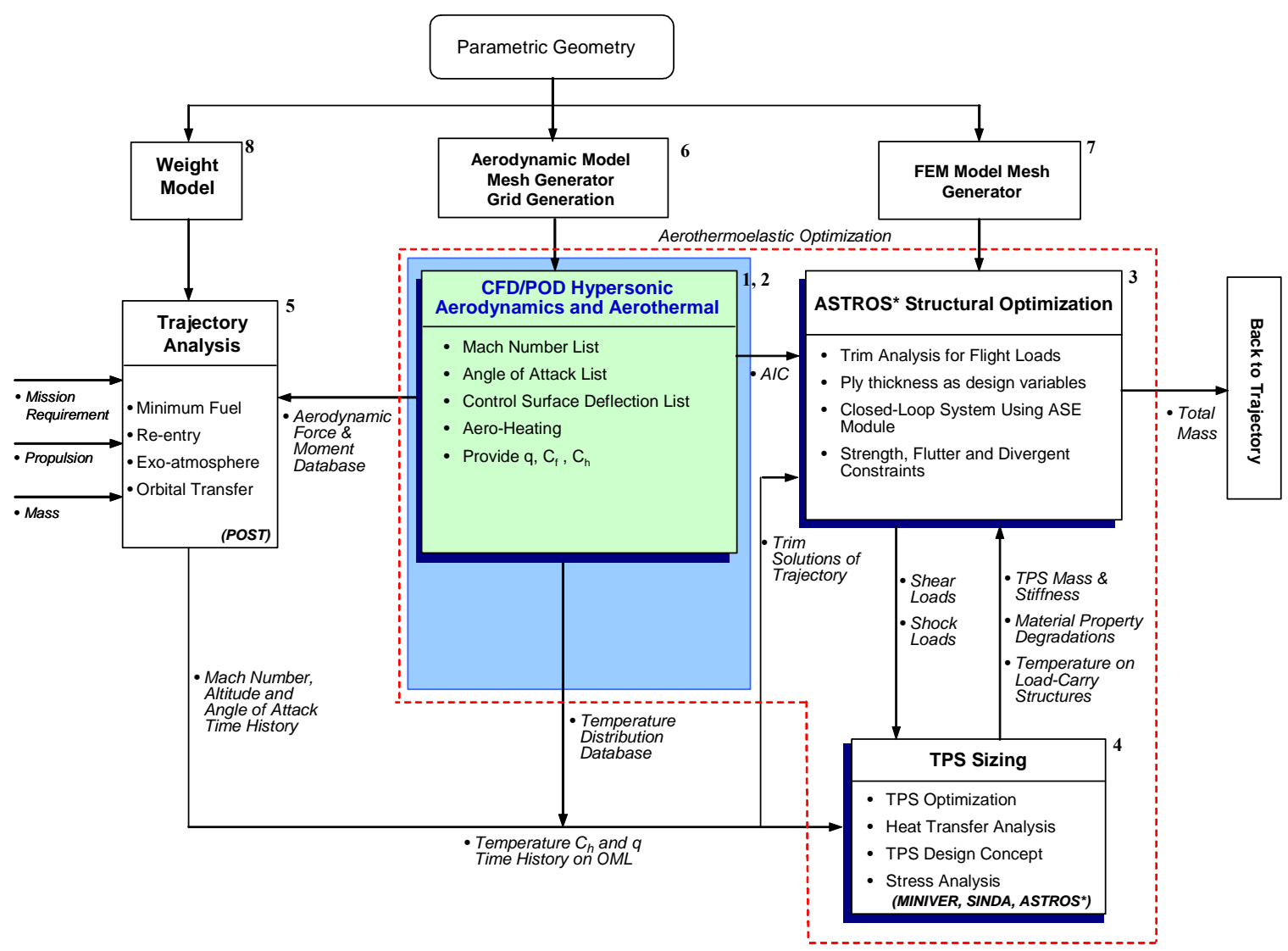

Figure 2. CFD/POD Module in the HYAAT system 


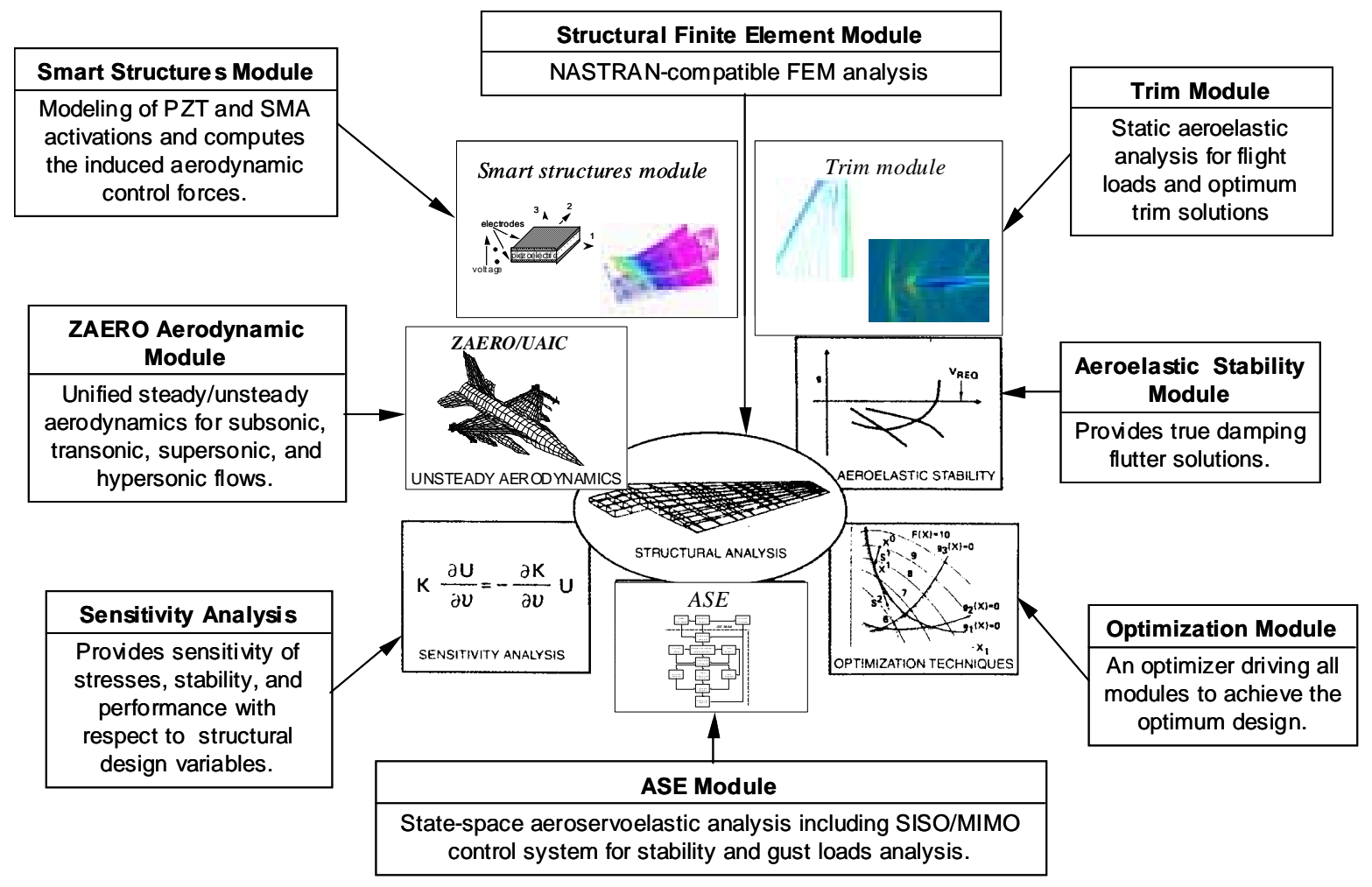

Figure 3. Automated Structures Optimization System (ASTROS*)

\begin{tabular}{|c|c|c|c|c|c|c|c|c|}
\hline & \multicolumn{7}{|c|}{$\begin{array}{l}\text { ZONAIR is a versatile tool for rapid aerodynamic database generation } \\
\text { - Aerodynamic AIC matrix readily coupled with FEM } \\
\text { - Force/moment coefficients } \\
\text { - Multi-body interference aerodynamics } \\
\text { - Accurate aerodynamics for aeroheating prediction }\end{array}$} & \multirow[b]{2}{*}{$\begin{array}{l}2 \text { Body Aero } \\
\text { Interference }\end{array}$} \\
\hline Code & Method & $\begin{array}{c}\text { Computational } \\
\text { Efficiency }\end{array}$ & $\begin{array}{l}\text { Streamline } \\
\text { Solution for } \\
\text { Aeroheating }\end{array}$ & $\begin{array}{c}\text { Hypersonic/ } \\
\text { Supersonic/ } \\
\text { Subsonic } \\
\text { Mach No. }\end{array}$ & $\begin{array}{l}\text { AIC for } \\
\text { Structur } \\
\text { al FEM }\end{array}$ & $\begin{array}{c}\text { Geometry } \\
\text { High } \\
\text { Fidelity }\end{array}$ & $\begin{array}{l}\text { High } \\
\text { AOA }\end{array}$ & \\
\hline CFD3D & Euler/N-S & $\begin{array}{c}30 \mathrm{hrs} / \\
\mathrm{X}-34\end{array}$ & Yes & All & No & Yes & Yes & Yes \\
\hline PANAIR & Potential & $\begin{array}{c}20 \mathrm{~min} / \\
\mathrm{X}-34\end{array}$ & No & $\begin{array}{l}\text { Supersonic/ } \\
\text { Subsonic }\end{array}$ & No & Yes & No & Yes \\
\hline ZONAIR & $\begin{array}{l}\text { Potential } \\
+ \text { PEF }\end{array}$ & $\begin{array}{c}20 \mathrm{~min} / \\
\mathrm{X}-34\end{array}$ & Yes & All & Yes & $\begin{array}{c}\text { Linear- } \\
\text { Order Panel }\end{array}$ & Yes & Yes \\
\hline ZAERO & $\begin{array}{c}\text { Potential + } \\
\text { PEF }\end{array}$ & $\begin{array}{c}10 \mathrm{~min} / \\
\mathrm{X}-34\end{array}$ & Yes & All & Yes & $\begin{array}{c}\text { Constant } \\
\text { Order Panel } \\
\end{array}$ & No & Yes \\
\hline$A P A S$ & $\begin{array}{c}\text { Potential }+ \\
\text { Empirical }\end{array}$ & $<10 \min$ & $\begin{array}{l}\text { Newtonian } \\
\text { S.L. }\end{array}$ & $\begin{array}{l}\text { Empirical for } \\
\text { hypersonics }\end{array}$ & No & $\begin{array}{l}\text { Low-Order } \\
\text { Panel }\end{array}$ & No & Yes \\
\hline MINIVER & $\begin{array}{c}\text { Analytical/ } \\
\text { Empirical }\end{array}$ & $<<10 \min$ & No & No subsonics & No & No & No & No \\
\hline DATCOM & $\begin{array}{c}\text { Analytical/ } \\
\text { Empirical }\end{array}$ & $<10 \min$ & No & All & No & No & Yes & No \\
\hline AP98 & $\begin{array}{c}\text { Analytical/ } \\
\text { Empirical }\end{array}$ & $\ll 10 \min$ & No & All & No & No & Yes & No \\
\hline
\end{tabular}

Figure 4. ZONAIR and CFL3D Capabilities vs Other Aerodynamic Codes 


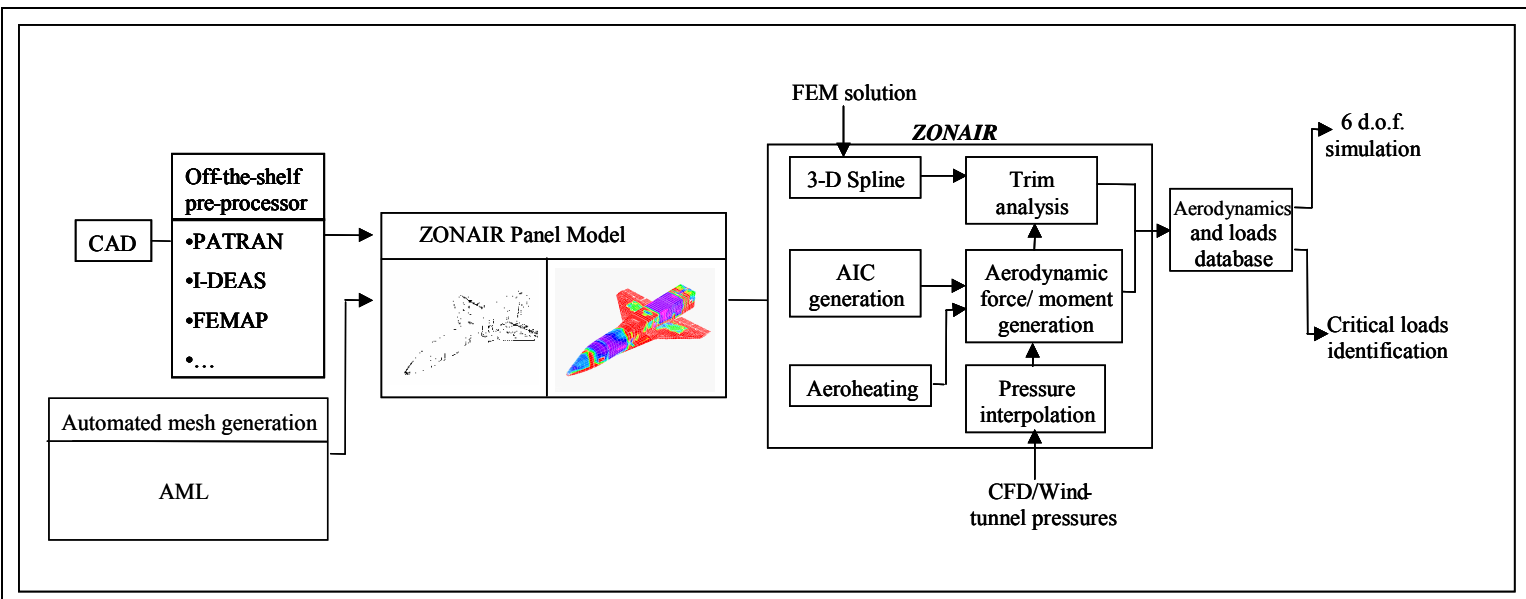

- Unified high-order subsonic/supersonic/hypersonic panel methodology

- Aerodynamic influence coefficient (AIC) matrix for rapid data retrieval

- Unstructured surface panel scheme compatible to the finite element method

- Rapid panel model generation using COTS/FEM pre- and post-processors

- Accurate streamline solution with axisymmetric analogy for aerothermodynamics

- Trim module for flexible loads and aeroheating module for TPS design/analysis

- Multibody interference/separation aerodynamics

- Pressure interpolation scheme for transonic flexible loads generation

- Aerodynamic database for 6 DOF simulation and critical loads identification

Figure 5. ZONAIR and It's Interfacing Capacity with Other FEM Software

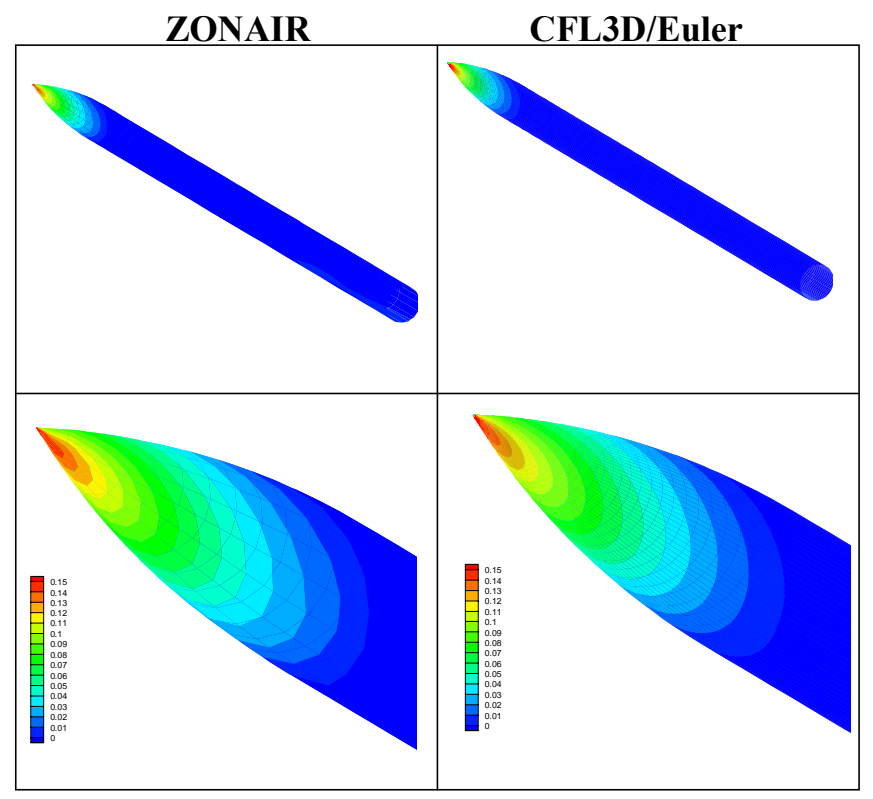

(a) Inviscid Surface Pressure Distribution

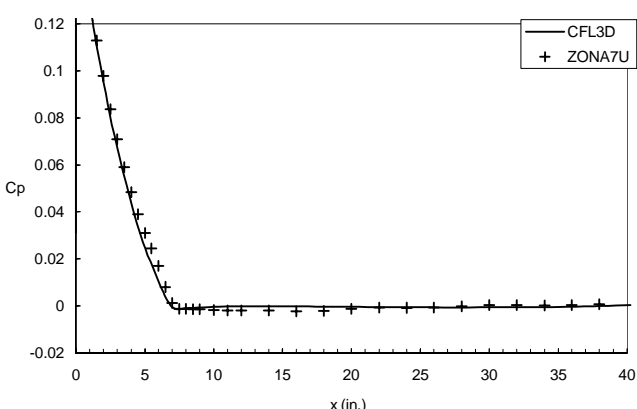

(b) Wind-Side Inviscid Surface Pressure

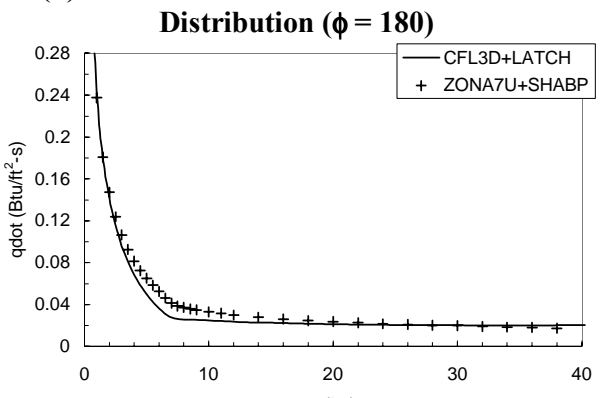

(c) Wind-Side Laminar Heat Transfer Rates $\left(\phi=180^{\circ}\right)$

Figure 6. Inviscid Surface Pressure and Laminar Heat Rate on CKEM at $\mathrm{M}_{\infty}=6.0, \alpha=2^{\circ}, p=2.66 \mathrm{lb}^{2} / \mathrm{ft}, T_{\infty}=89.971^{\circ} \mathrm{R}, T_{w}=540^{\circ} \mathrm{R}$ 


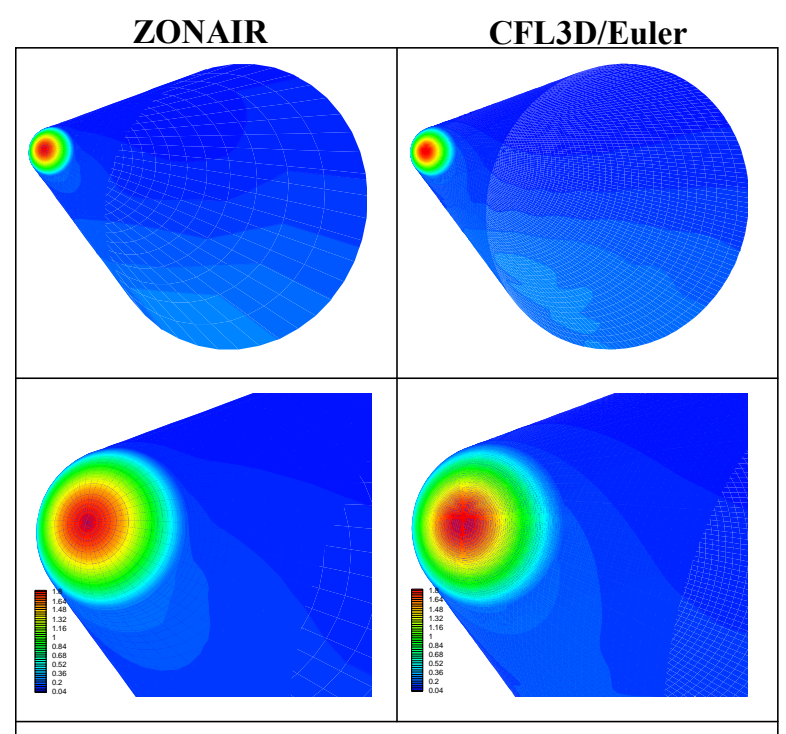

(a) Inviscid Surface Pressure Distribution
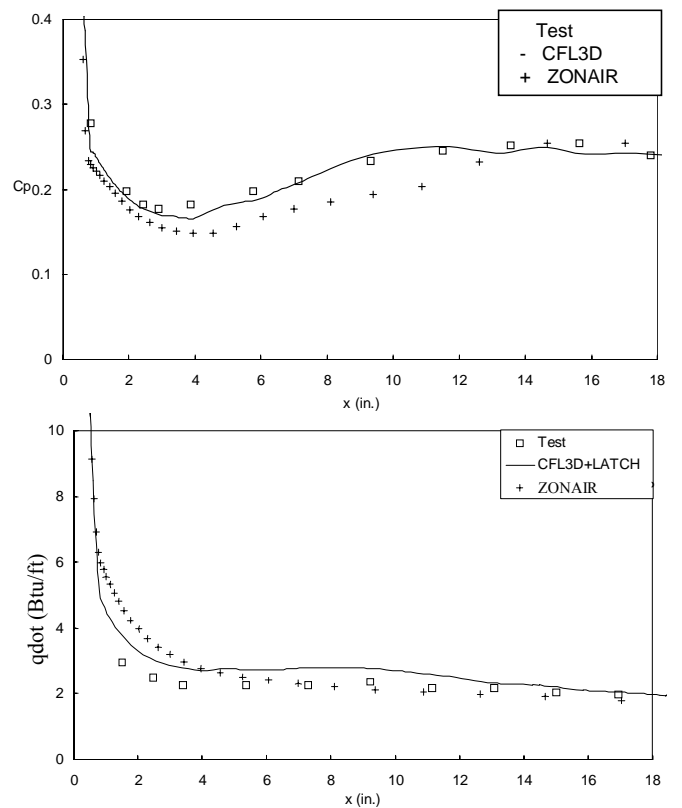

(b) Wind-Side Laminar Heat Transfer Rates $\left(\phi=180^{\circ}\right)$

Figure 7. Inviscid Surface Pressure and Laminar Heat Rate on a $15^{\circ}$ Blunt Cone at $\mathrm{M}_{\infty}=10.6, \alpha=5^{\circ}, p=2.66 \mathrm{lb}^{2} / \mathrm{ft}, T_{\infty}=89.971^{\circ} \mathrm{R}, T_{w}=540^{\circ} \mathrm{R}$

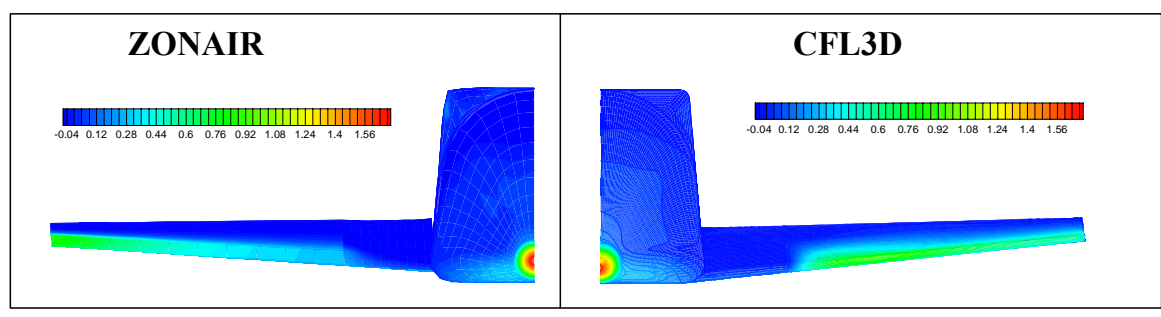

Front View
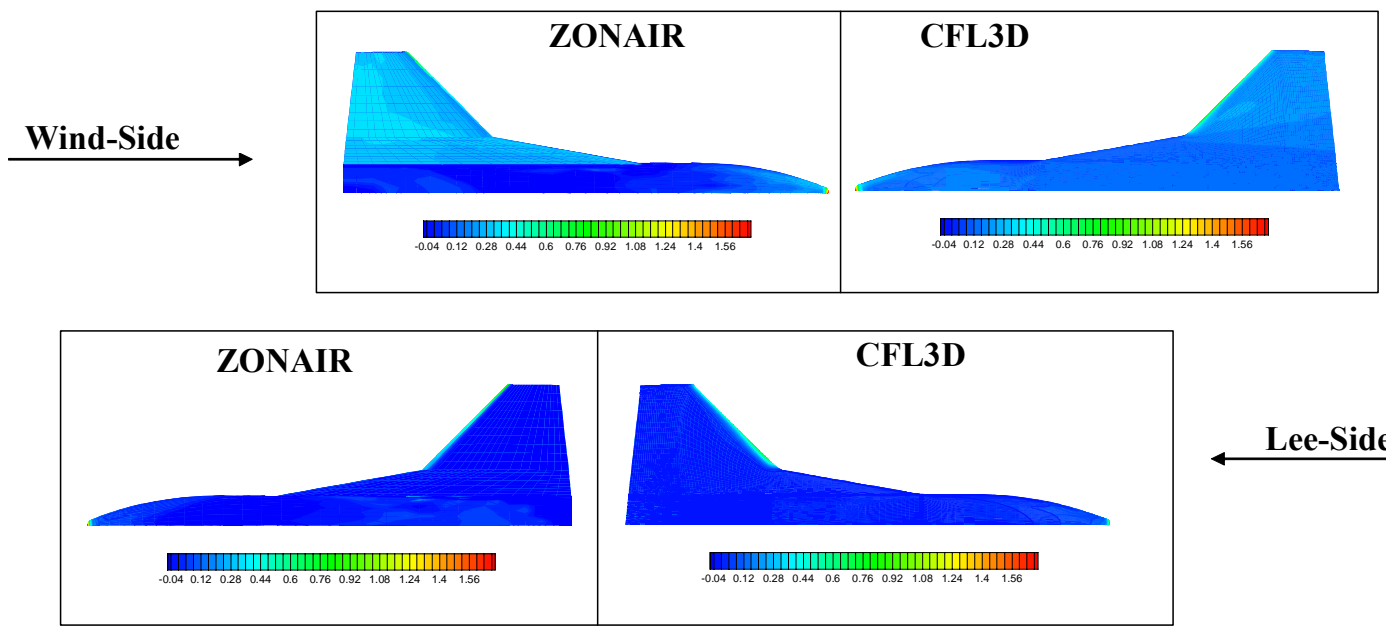

Lee-Side

Figure 8. $X-34$ Wing-Body: Aerodynamics at $M_{\infty}=6.0, \alpha=15.22^{\circ}$ 


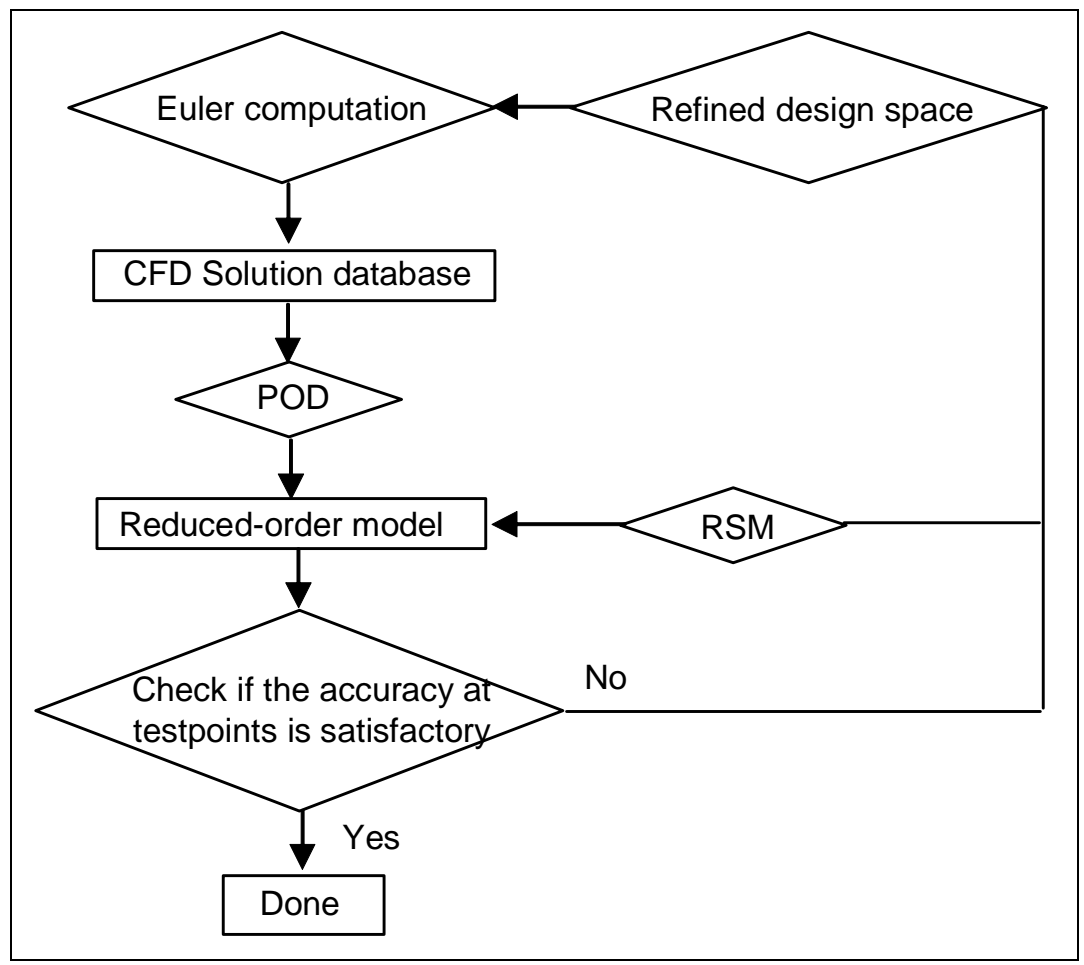

Figure 9. Road Map of the POD/RSM Methodology

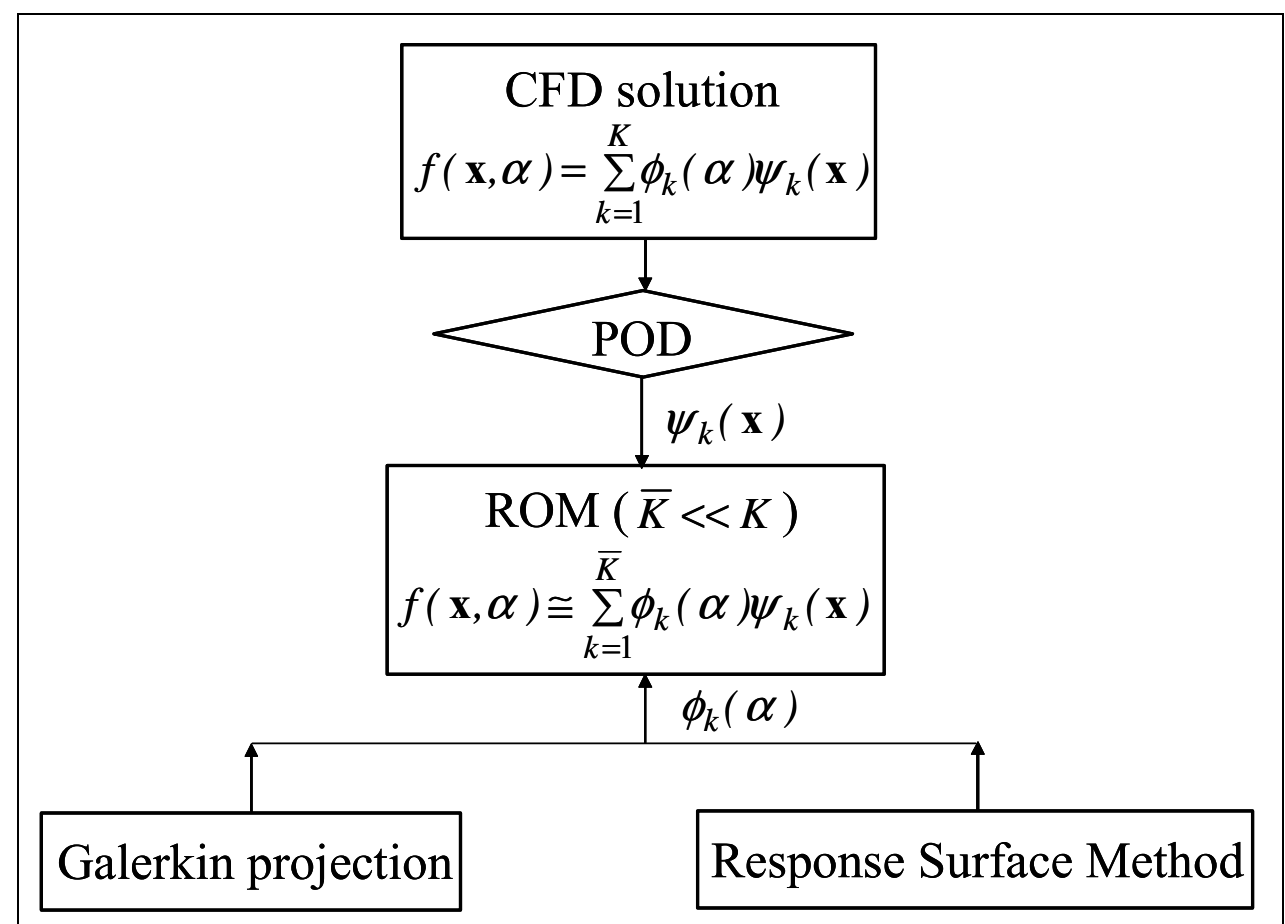

Figure 10. Proper Orthogonal Decomposition (POD) and Response Surface Method (RSM) Interrelation 
- A quasi-steady variation of AoA is assumed whereby the AoA is treated in a time-like manner

$$
f(\mathbf{x}, \alpha)=\sum_{k=1}^{K} \phi_{k}(\alpha) \psi_{k}(\mathbf{x})
$$

- POD is the technique used to extract those principal basis functions from the extensive CFD results:

$$
\text { Minimize norm of } E_{\bar{K}}(\mathbf{x}, \alpha)=f(\mathbf{x}, \alpha)-f^{\bar{K}}(\mathbf{x}, \alpha)
$$

Above series truncated with $\bar{K}$ eigenmodes

Rapid convergence $\longrightarrow$ Reduced-order probing

$$
f(\mathbf{x}, \alpha) \begin{gathered}
\text { Scalar/vector } \\
\text { flow variable }
\end{gathered} \Psi_{k}(\mathbf{x}) \begin{gathered}
\text { Scalar/vector } \\
\text { basis function }
\end{gathered} \phi_{k}(\alpha) \begin{gathered}
\text { Scalar } \\
\text { coefficient }
\end{gathered}
$$

Figure 11. Proper Orthogonal Decomposition

- Scalar coefficient surface for:
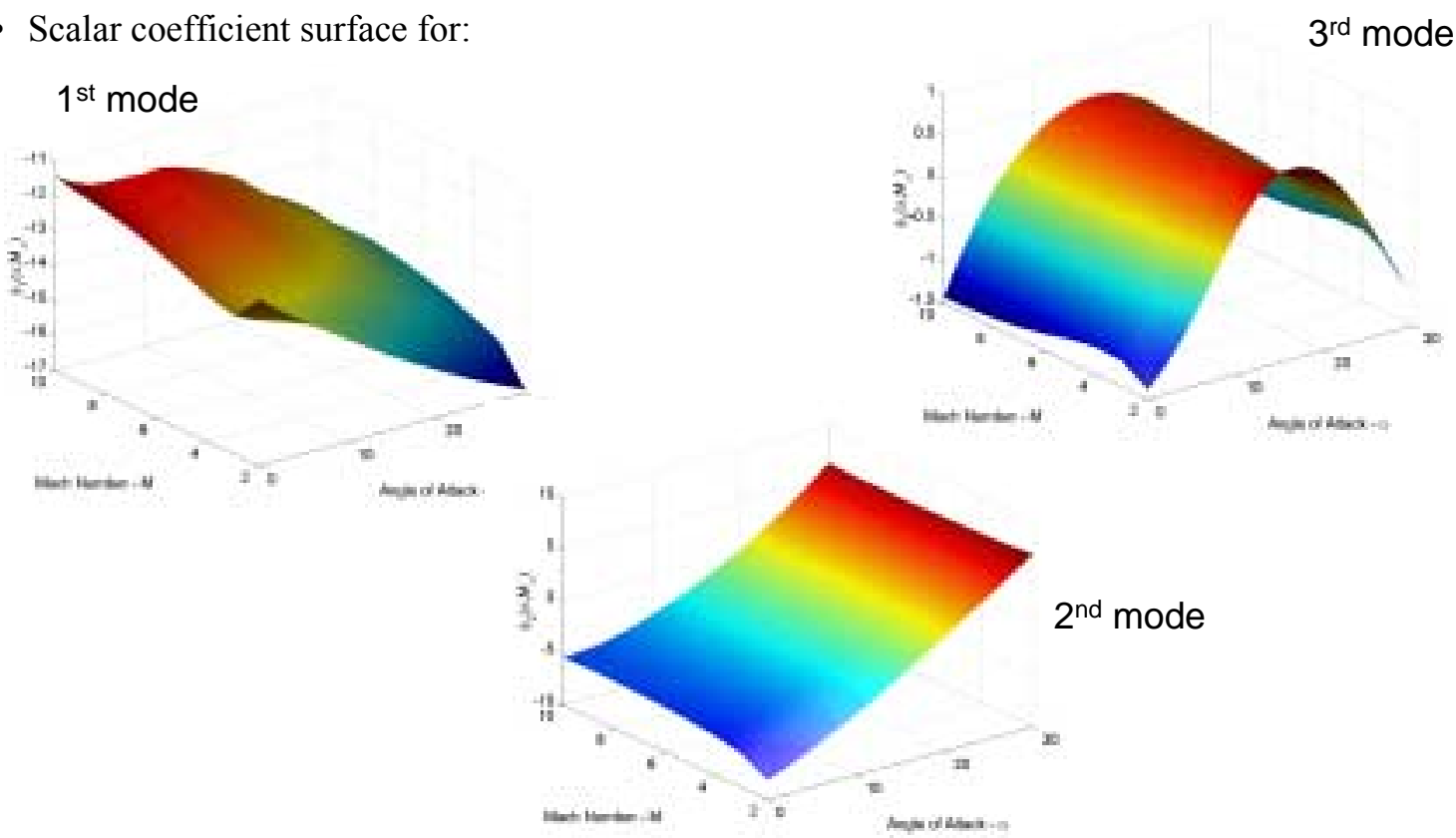

Figure 12. Response Surface Method Based on 3 POD Mode Solutions for a Modeled X-34 


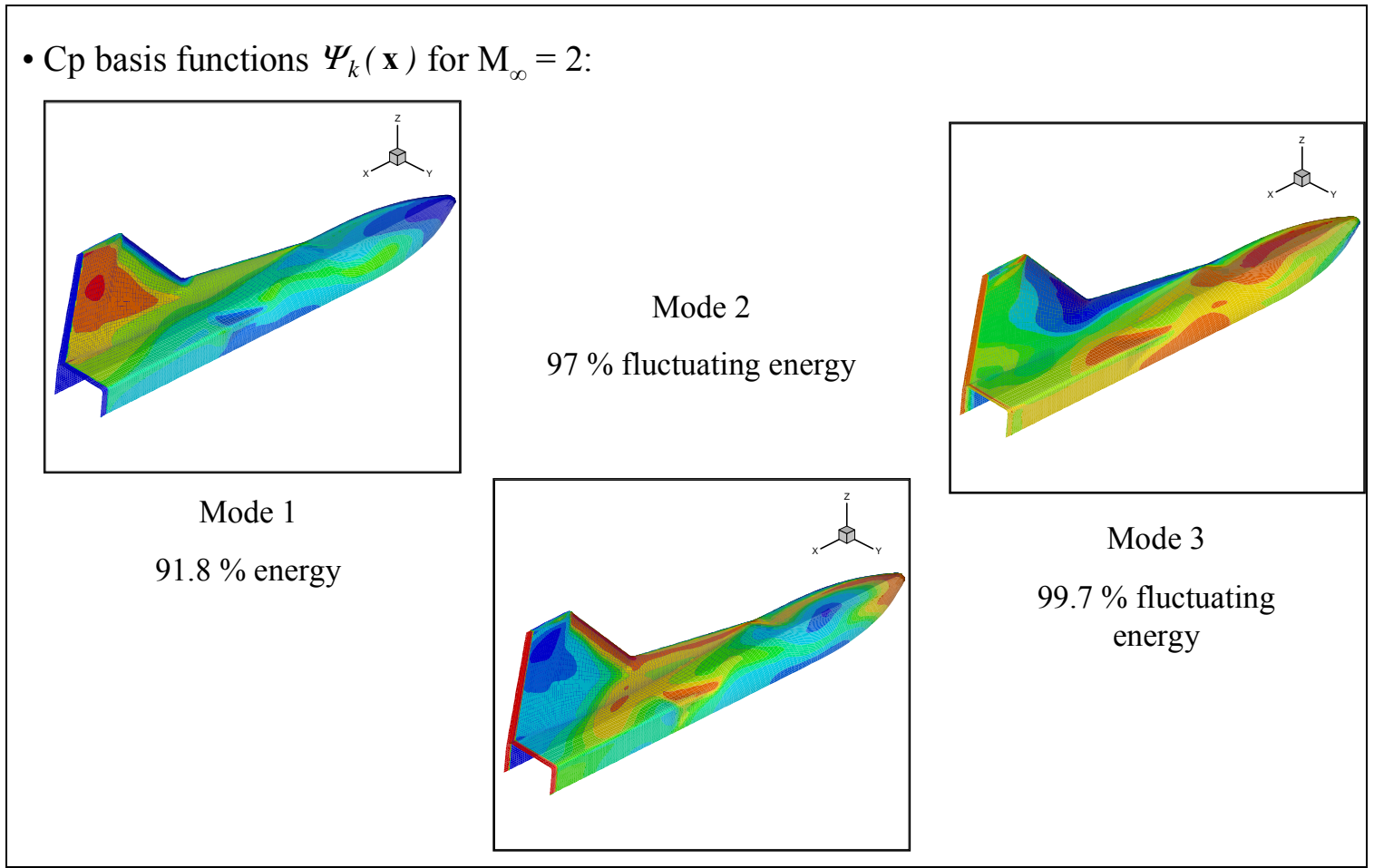

Figure 13. POD Reduced Order Modes

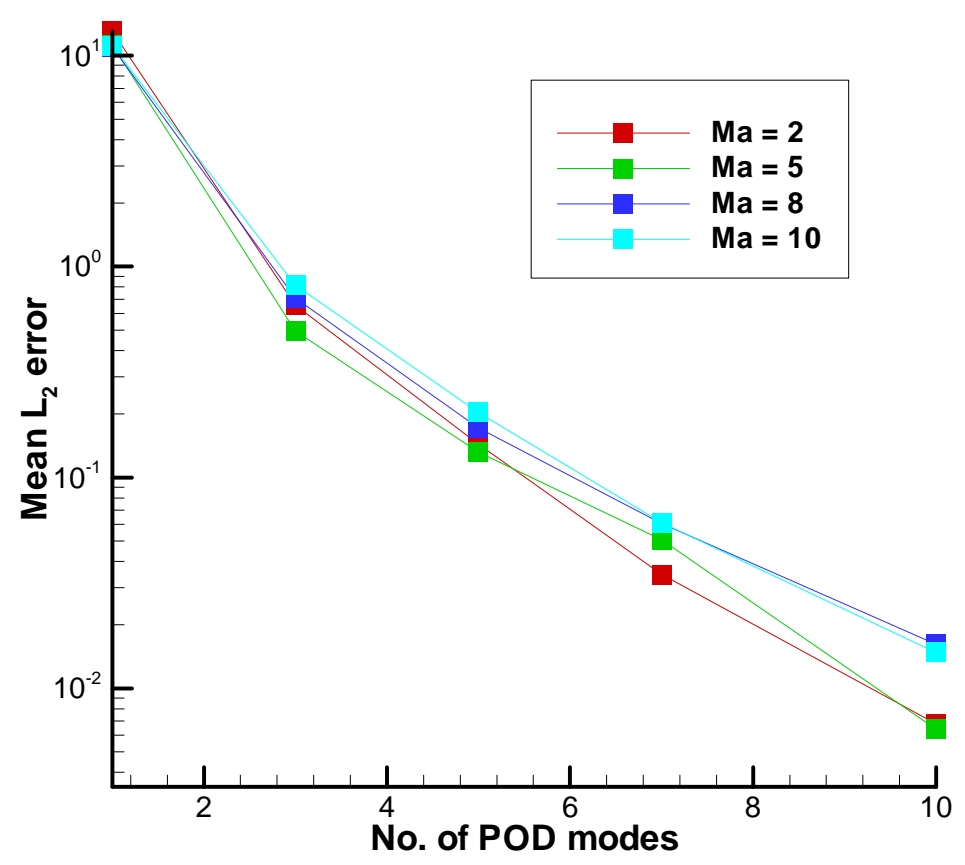

Figure 14. POD Solution Convergence Overall Convergence: 3 POD modes capture 99.99\% energy for all Mach numbers 


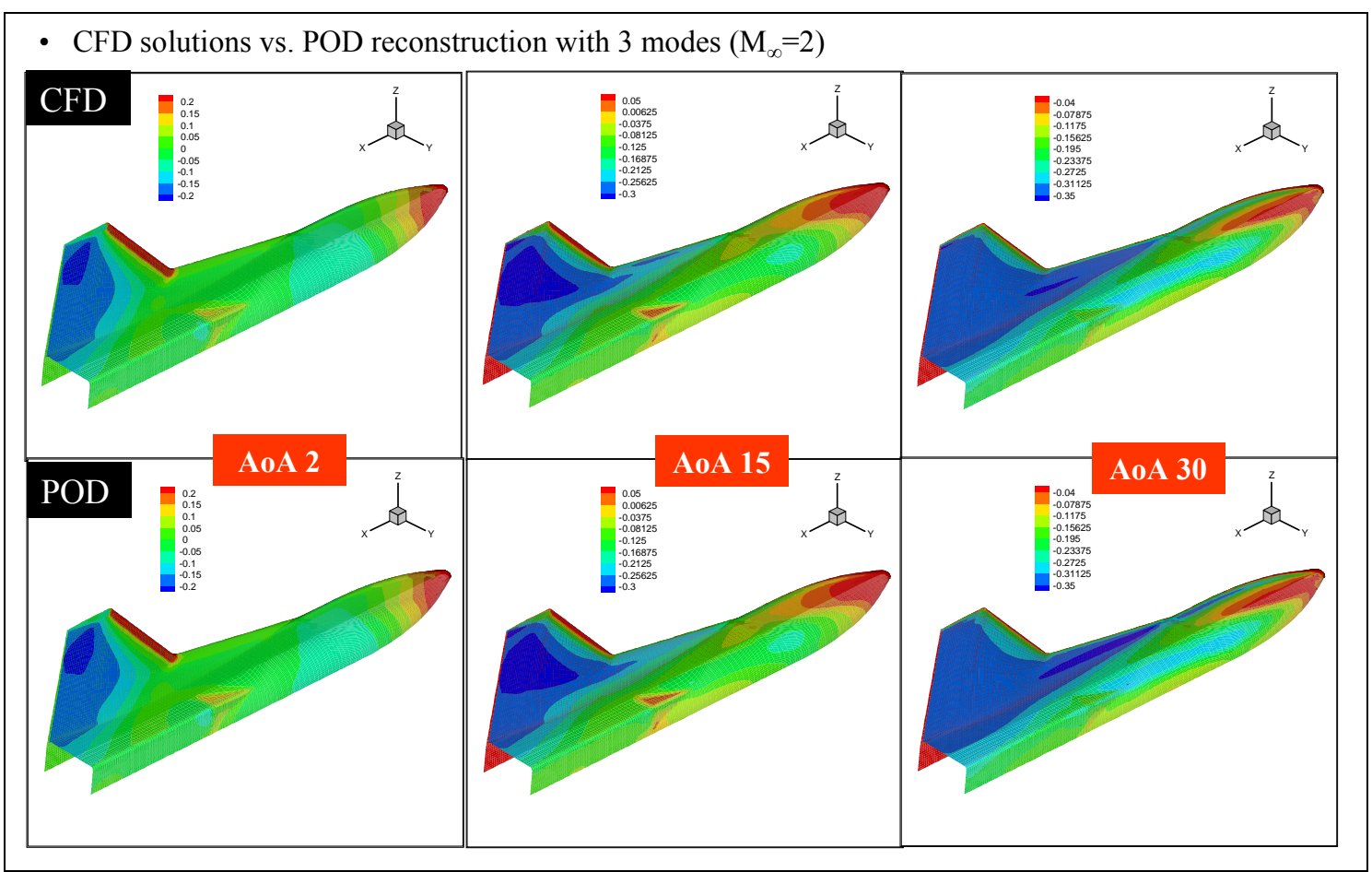

Figure 15. POD/RSM Solution (1)

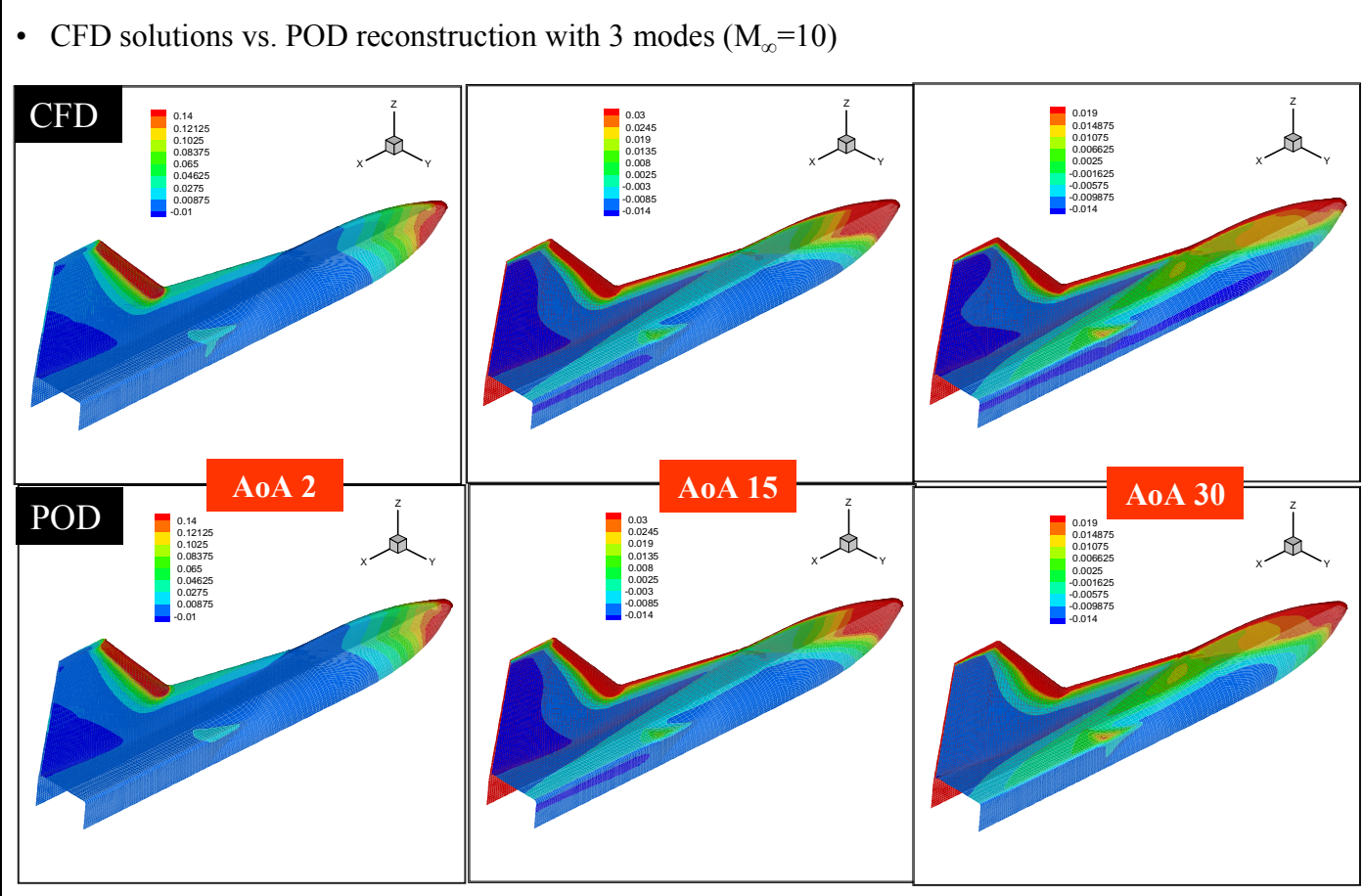

Figure 16. POD/RSM Solution (2) 


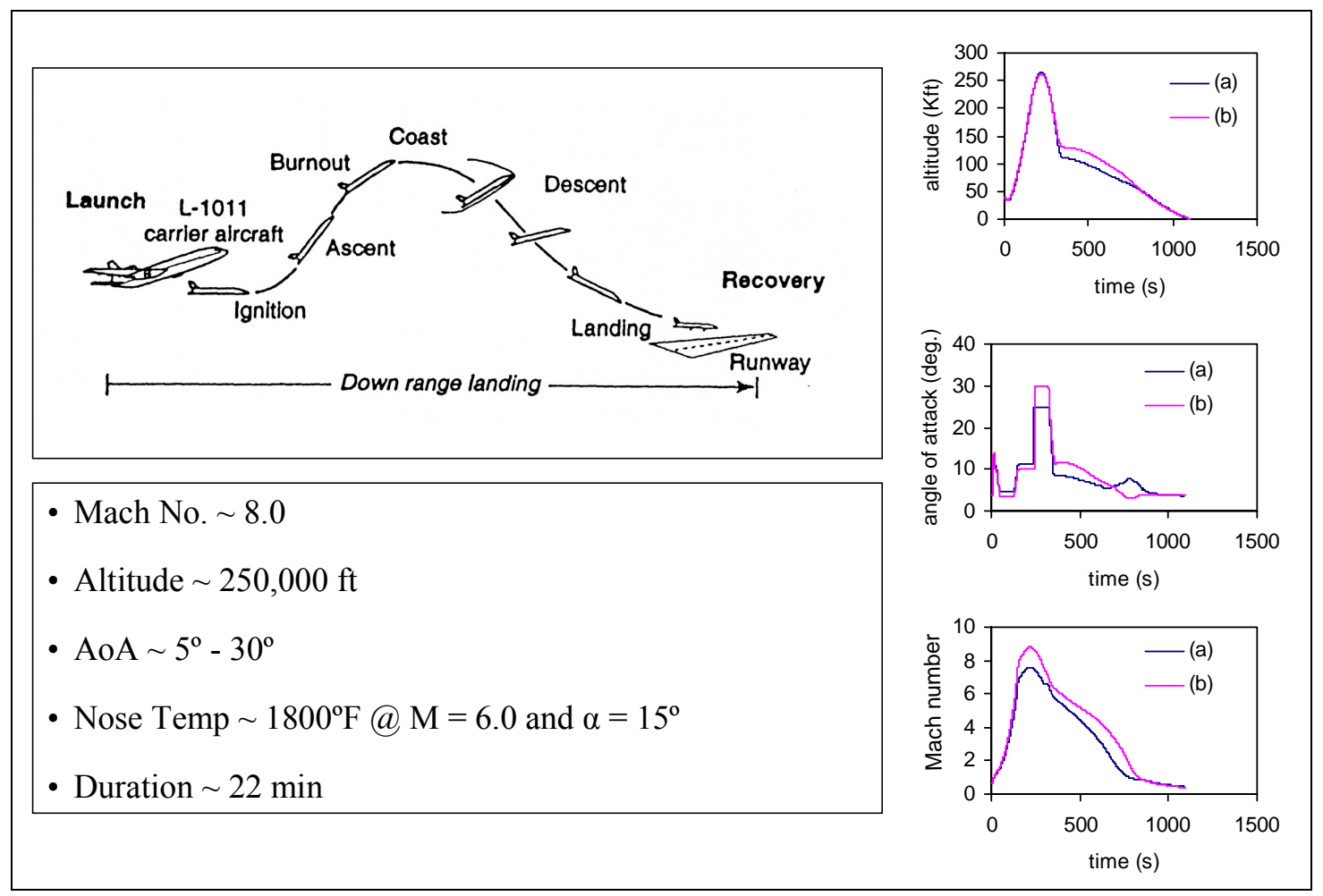

Figure 17. Typical X-34 Mission Profile

(a) X1004601, (b) X1004701, Trajectory and Flight Condition History

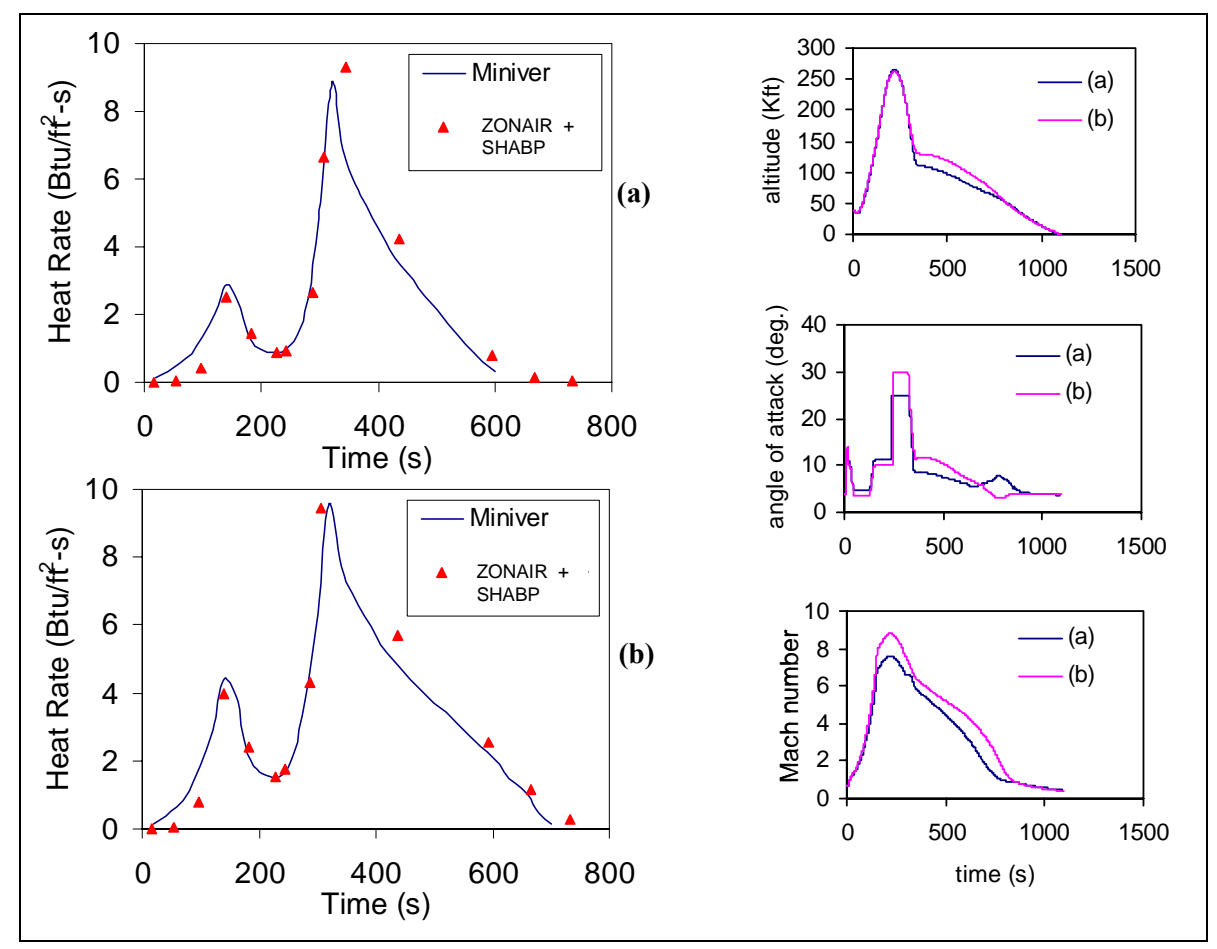

Figure 18. Heat Rate Comparison at Stagnation Point (a) X1004601, (b) X1004701, Trajectory and Flight Condition History 


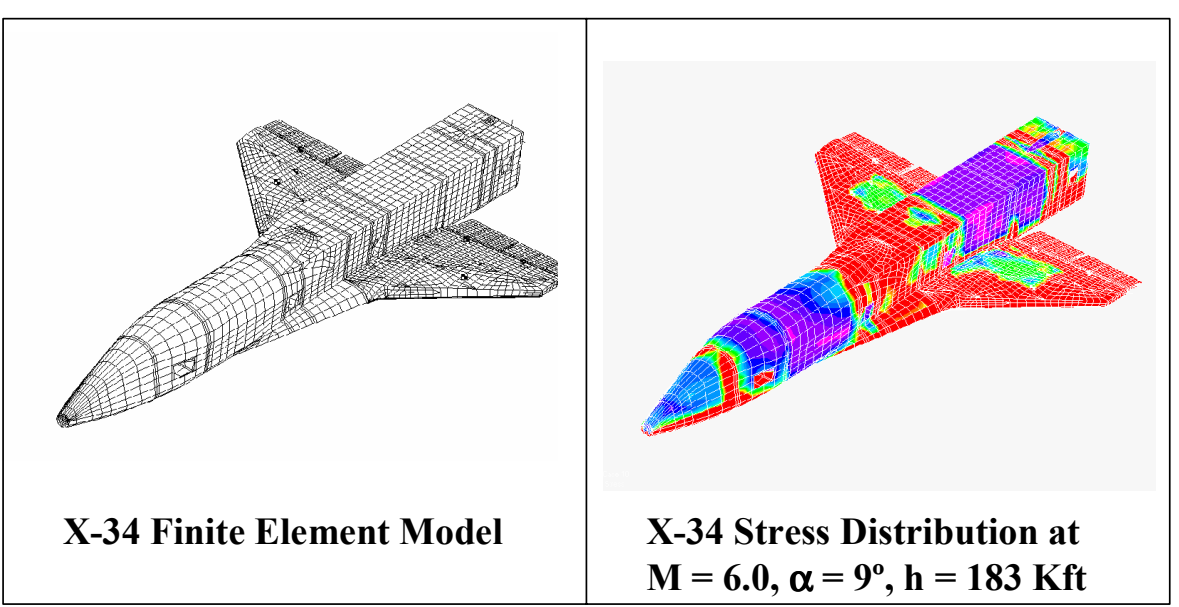

- X-34 ASTROS* FEM Model was converted from MSC/NASTRAN Model provided by Orbital/OSC

- TRIM condition is at $\mathrm{M}=6.0, \alpha=9^{\circ}, \mathrm{h}=183 \mathrm{Kft}$.

- TRIM results for total weight of $16,000 \mathrm{lbs}$.

- $\mathrm{N}_{\mathrm{z}}=0.97 \mathrm{~g}$.

- Trailing Edge Flap $=2.05^{\circ}$

\section{Figure 19. X-34 Trim Analysis Using ASTROS*}

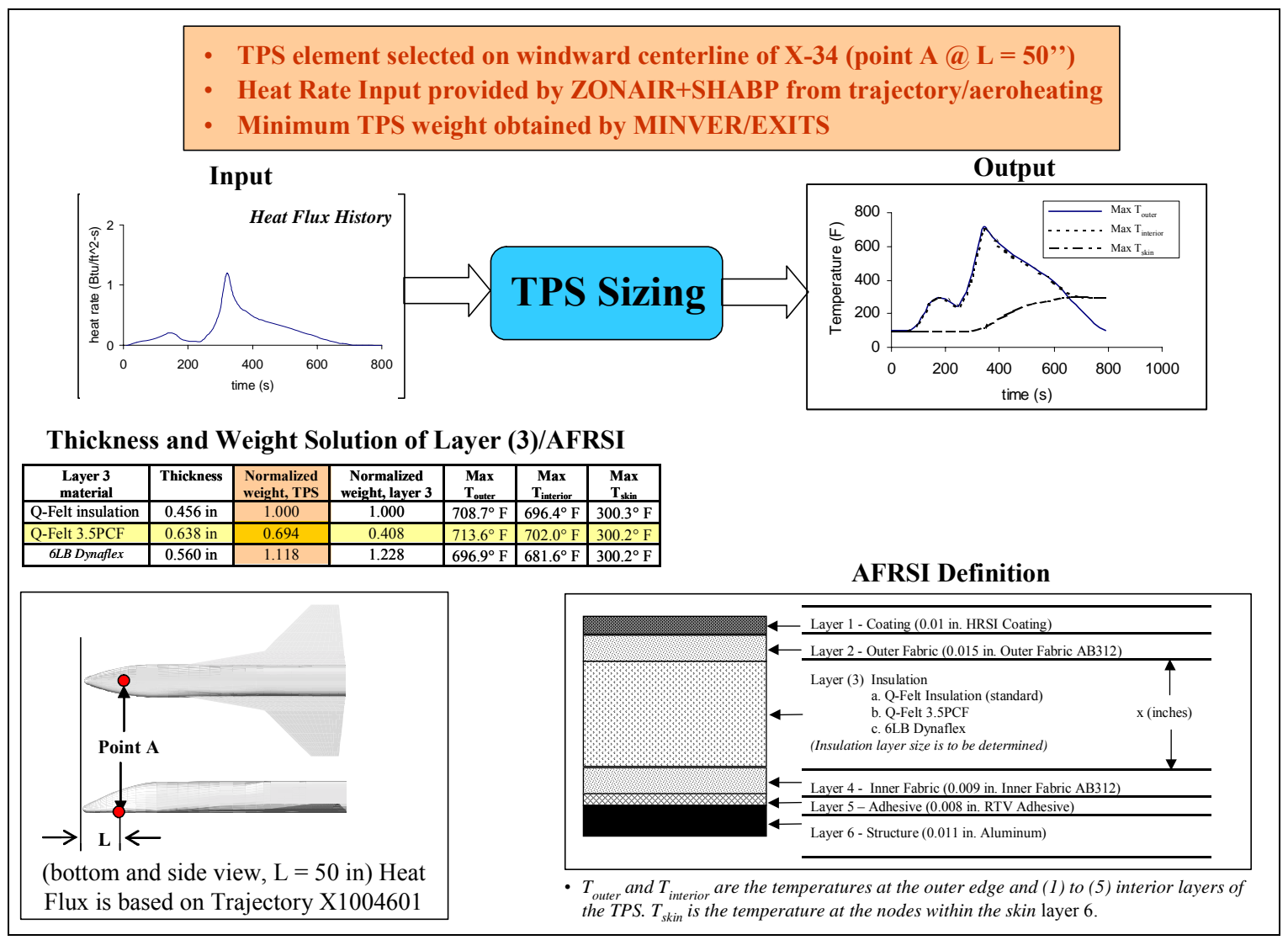

Figure 20. Elementary TPS Sizing of AFRSI 
- TPS sizing will be automated by developing an optimization driver of the MINIVER/EXITS code.

- For a given heat flux $\dot{q}$ applied on the outer boundary, the objective is to minimize the total weight of the TPS system while keeping the temperature at each layer $\left(T_{i}\right)$ below their respective maximum operational temperature, $T_{o i}$.

- Minimize: $W=\sum_{i=1}^{n} \rho_{i} h_{i}$ where $\rho_{i}$ is the density of the $i^{t h}$ layer.

Subjected to: $T_{i}<T_{o i} \quad i=1,2 \ldots n$

Design variables: $h_{\max i}>h_{i}>h_{\min i} i=1,2 \ldots n$

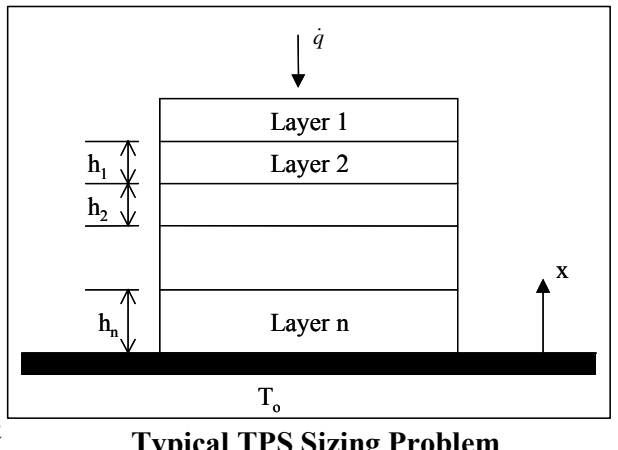

- The complex-variable differentiation can provide "numerically exact" derivatives of a complicated function.

-The variable $h$ of a real function $T(h)$ is replaced by $h+i \Delta h$.

-For small $\Delta h: \quad T(h+i \Delta h)=T(h)+i \Delta h \frac{\partial T}{\partial h}+\ldots \quad$ Yields: $\frac{\partial T}{\partial h}=\frac{\operatorname{Im}(T(h+i \Delta h))}{\Delta h}+0\left(\Delta h^{2}\right)$

- To incorporate the complex variable technique into the MINIVER/EXITS module for sensitivity analysis is straightforward simply by declaring all variables in the MINIVER/EXITS module as complex variables.

-The imaginary part of the thickness input of MINIVER/EXITS represents a small incremental thickness.

-The sensitivity is the imaginary part of the temperature output divided by the incremental thickness.

Figure 21. TPS Sizing Optimization using Complex-Variable Differentiation Sensitivity

\section{Validation of complex variable differentiation for sensitivity}

- Temperature change at Layer 6 due to the change of thickness of layer $3\left(\partial \mathrm{T}_{6} / \partial \mathrm{h}_{3}\right)$ is computed using both the Complex Variable Differentiation (CV) and the Finite Difference (FD) techniques.

- In order to demonstrate the robustness of the $\mathrm{CV}, \Delta \mathrm{h}_{3}=10^{-30}$ (near machine zero) is assigned for the $\mathrm{CV}$ technique whereas $\Delta \mathrm{h}_{3}$ for the FD technique varies from $10^{-2}$ to $10^{-6}$.

- Results show that the accuracy of the FD technique depends on $\Delta \mathrm{h}_{3}$ but the $\mathrm{CV}$ technique does not.

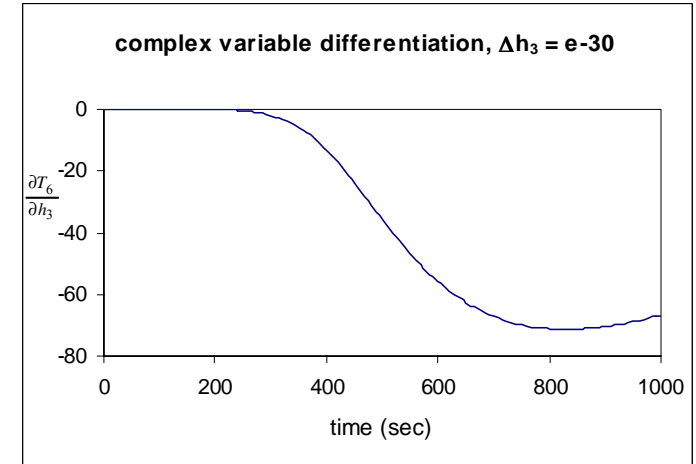

relative error of sensitivity at layer $6(\mathrm{FD}-\mathrm{CV}) / \mathrm{CV}$

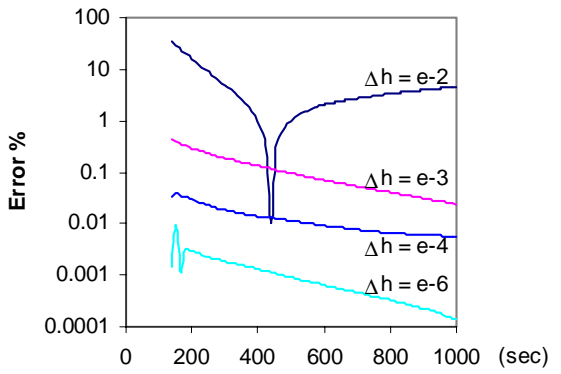

Figure 22. Development of an Optimization Procedure for TPS Sizing 


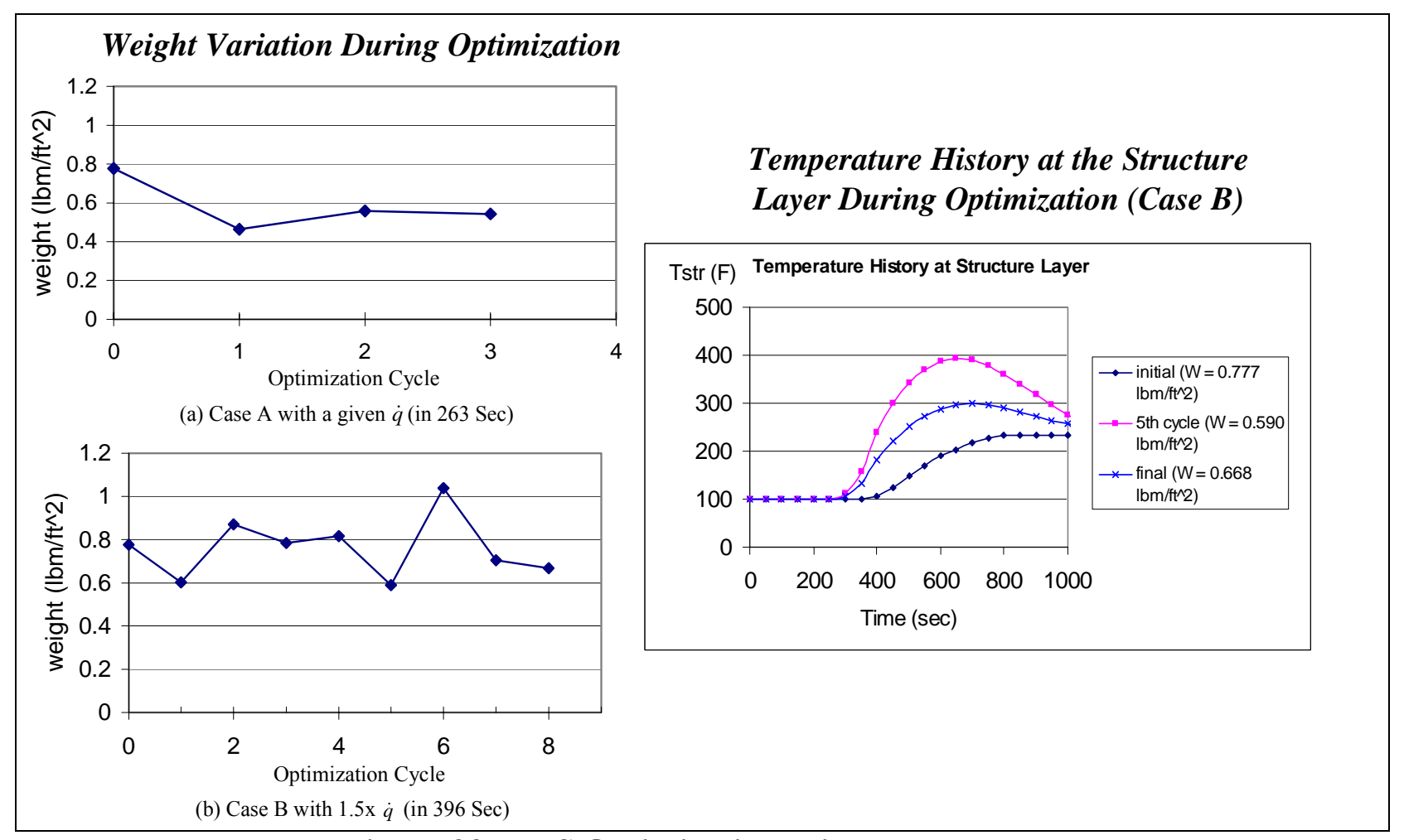

Figure 23. TPS Optimization using MINIVER

- All design variables reduce to the minimum thickness (0.0072") except layer 3 $\left(\mathrm{h}_{3}=0.68496 "\right)$.

- The total weight is reduced from the initial weight $=0.777 \mathrm{lbs} / \mathrm{ft}^{2}$ to the final weight $=$ $0.54256 \mathrm{lbs} / \mathrm{ft}^{2}$

\begin{tabular}{|c|l|c|c|c|c|c|c|}
\hline Layer & \multicolumn{1}{|c|}{ Material } & $\begin{array}{c}\text { Temp limit } \\
\left({ }^{\circ} \mathrm{F}\right)\end{array}$ & $\begin{array}{c}\text { Density } \\
\left(\mathrm{lbm} / \mathrm{ft}^{\wedge} \text { 3) }\right.\end{array}$ & $\begin{array}{c}\text { Specific Heat } \\
\left(\mathrm{But} / \mathrm{lbm}{ }^{\circ} \mathrm{F}\right)\end{array}$ & $\begin{array}{c}\text { Initial } \\
\text { thickness (in) }\end{array}$ & $\begin{array}{c}\text { Max temp in } \\
\left.\text { the layer ( }{ }^{\circ} \mathrm{F}\right)\end{array}$ & $\begin{array}{c}\text { Optimized } \\
\text { design (in) }\end{array}$ \\
\hline 1 & HRSI Coating & 2300 & 104 & 0.20 & 0.01 & 705.2 & 0.0072 \\
\hline 2 & AB312 Fabric & 2024 & 61.5 & 0.166 & 0.015 & 704.9 & 0.0072 \\
\hline 3 & Q-Felt & 1800 & 3.5 & 0.1875 & 1.2 & 701.6 & 0.68496 \\
\hline 4 & AB312 Fabric & 2024 & 61.5 & 0.166 & 0.009 & 300.0 & 0.0072 \\
\hline 5 & RTV-560 & 550 & 88 & 0.285 & 0.008 & 300.0 & 0.0072 \\
\hline 6 & Aluminum & 300 & 173 & 0.22 & 0.011 & 300.0 & 0.011 \\
\hline
\end{tabular}

Note: For structure layer (6), thickness is not a design variable.

upper bound thickness $=1.0$ in, lower bound $=0.0072$ in with original heat flux of X1004601 trajectory

Figure 24. Development of an Optimization Procedure for the TPS Sizing Optimization Results with upper bound $=1$ inch and lower bound at 0.0072 inch 
- Simplified X-34 wing-body

configuration consists of a body with round nose of 7.0" radius, a strake, and a swept wing.

- The surface mesh consists of 1554 panels and 1559 grid points

-The aerodynamic database is generated by running ZONAIR for 68 combinations of 4 Mach numbers $(2,5$, $8,10)$ and 17 angles of attack $(0,6,10$, $13,15,17,19,21,22-30)$.

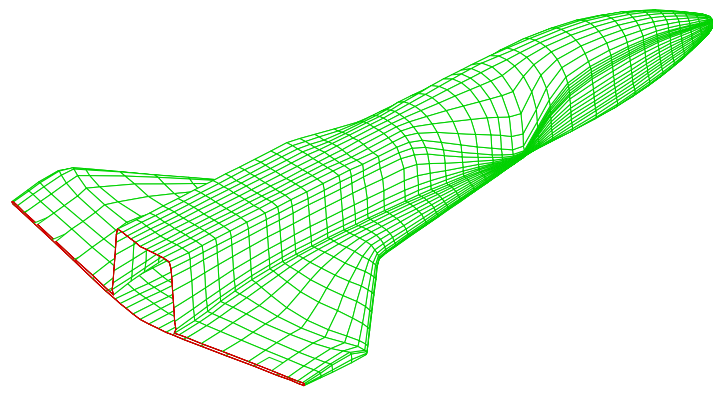

Figure 25. Surface Panels on TPS of Simplified X-34 (Based on X1004701 Trajectory/Flight Conditions)

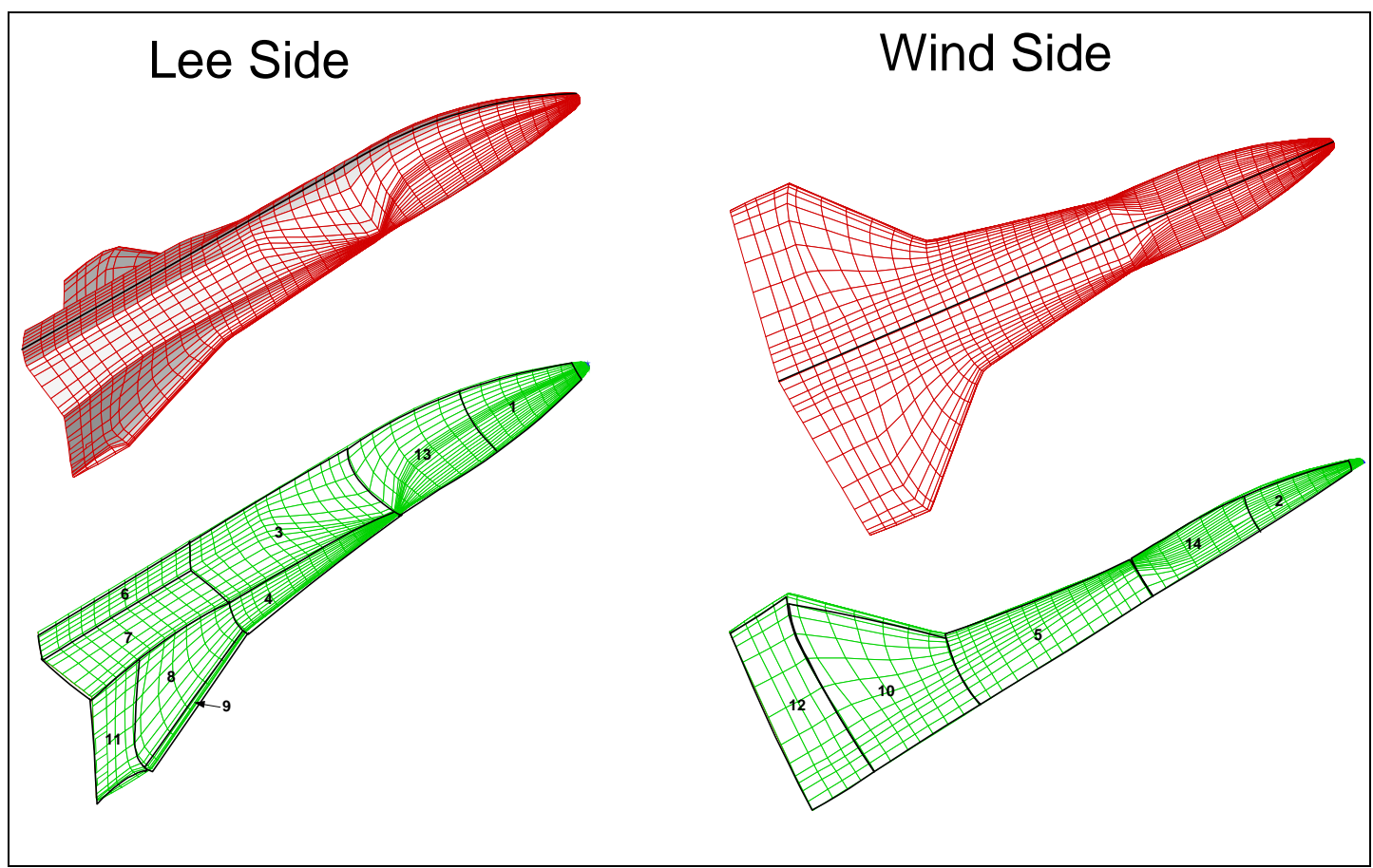

Figure 26. Design Patches of Half of Lee Side/Wind Side X-34 (Based on X1004701 Trajectory/Flight Conditions) 
- Fourteen patches are defined over the TPS system for the X-34 configuration, among which the patches $2,5,10,12$ and 14 are defined on the lower surface and patch 9 is located over the leading edge of the horizontal wing.

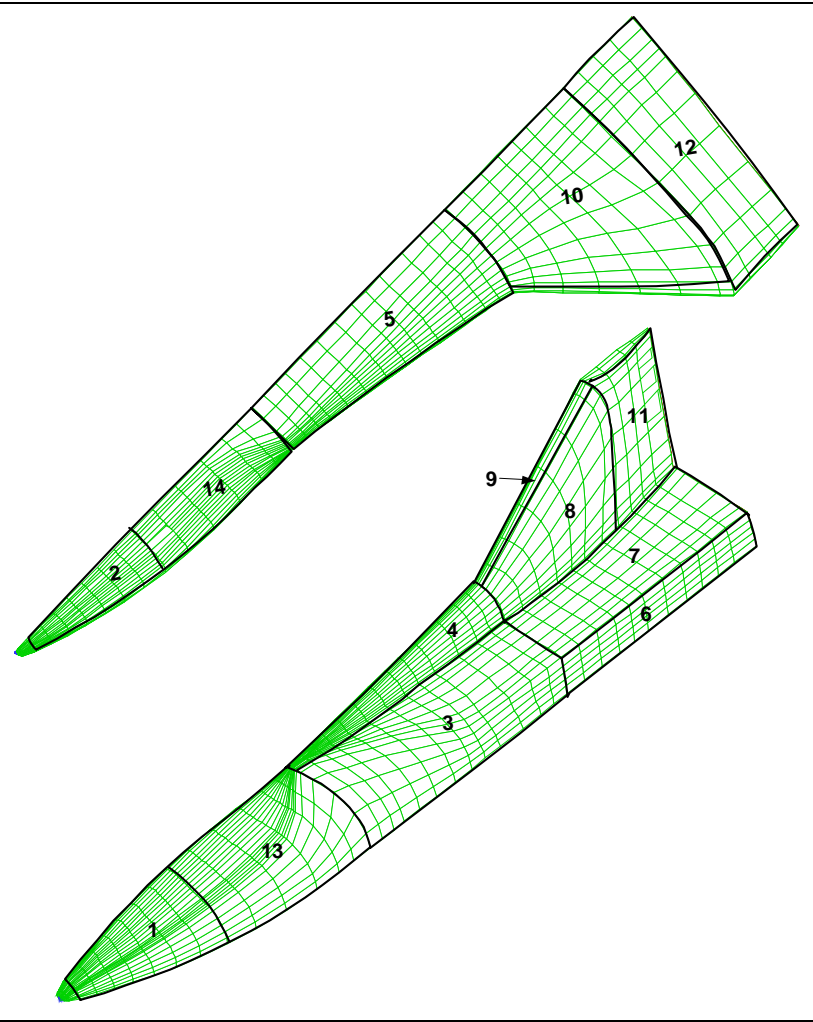

Figure 27. Design Patched Defined over TPS (Based on X1004701 Trajectory/Flight Conditions)
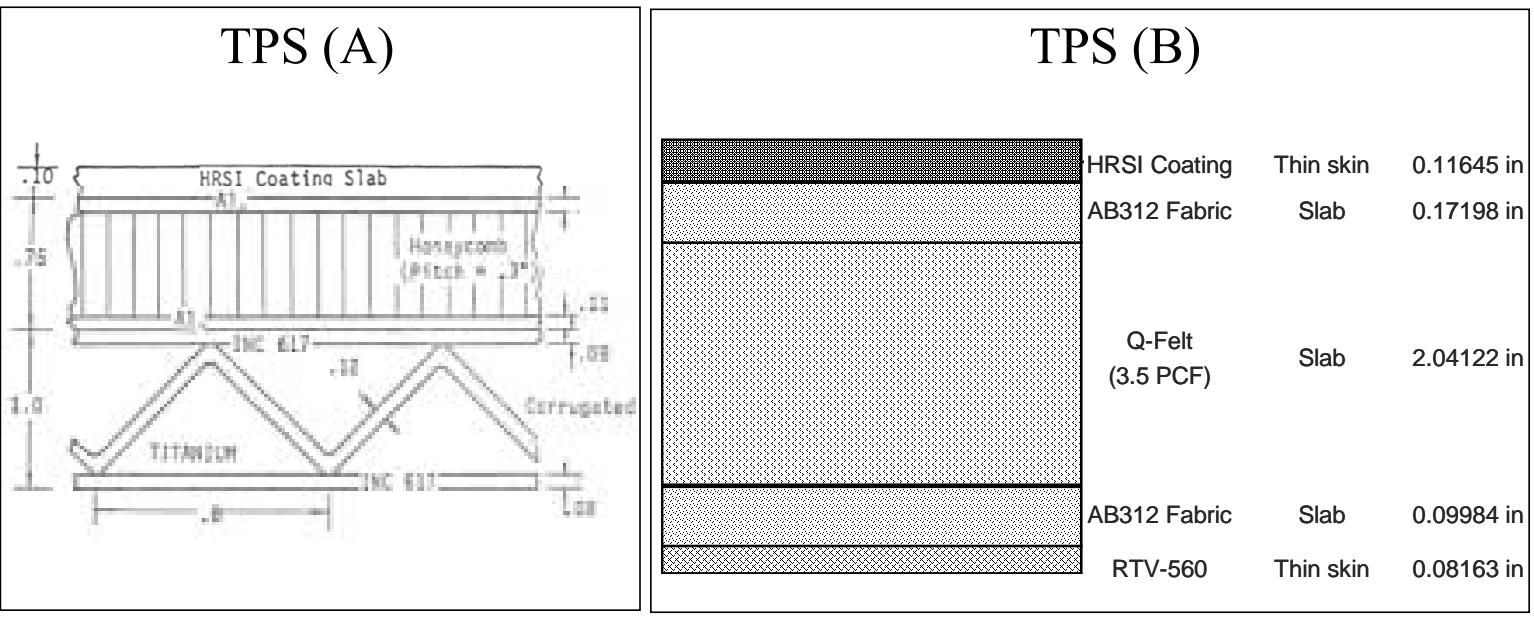

Figure 28. TPS for New Cases Studied: TPSOPT -initial (Based on X1004701 Trajectory/Flight Conditions) 


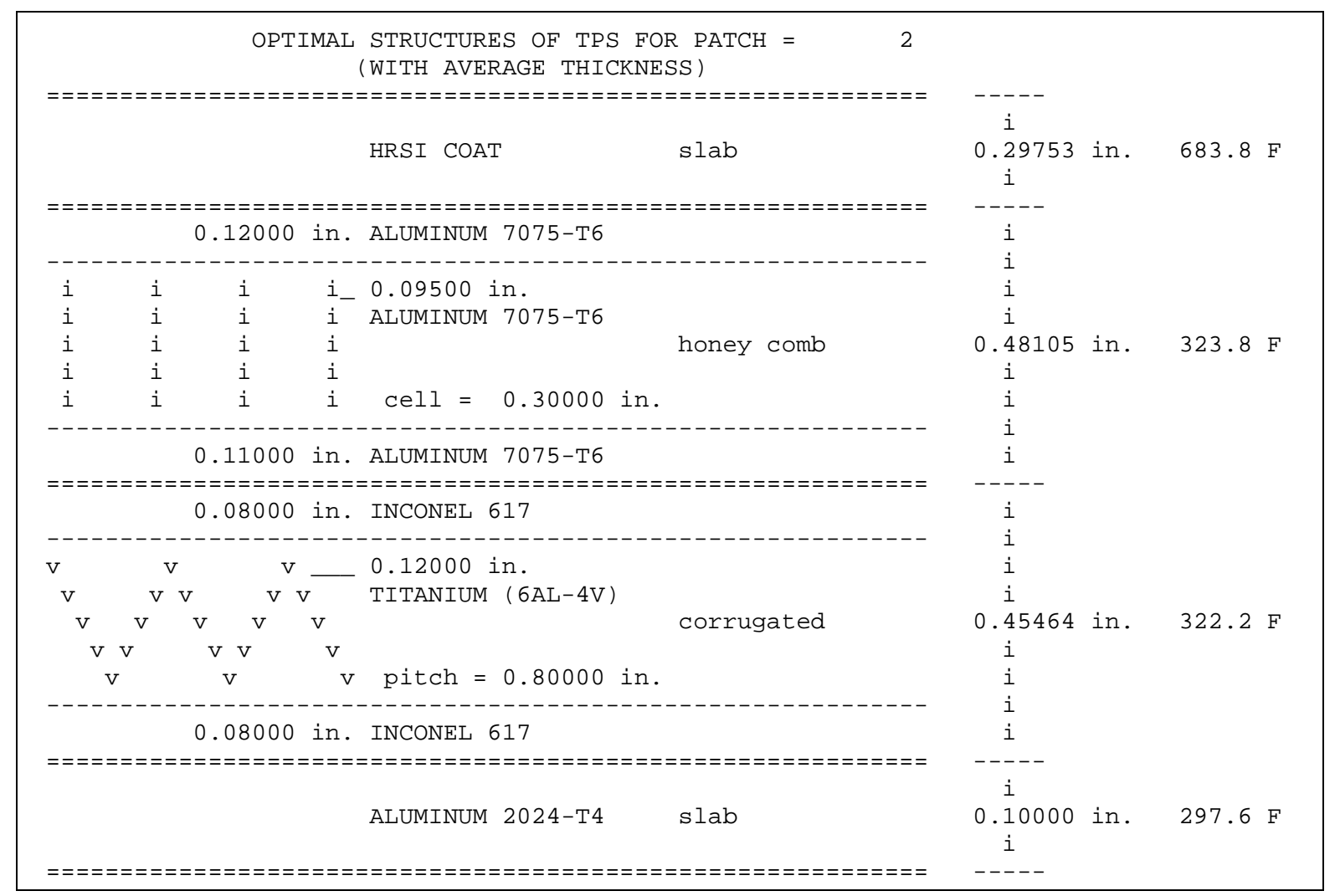

Figure 29. TPS - (A) for Nose Part and Leading Edge - final (Based on X1004701 Trajectory/Flight Conditions)

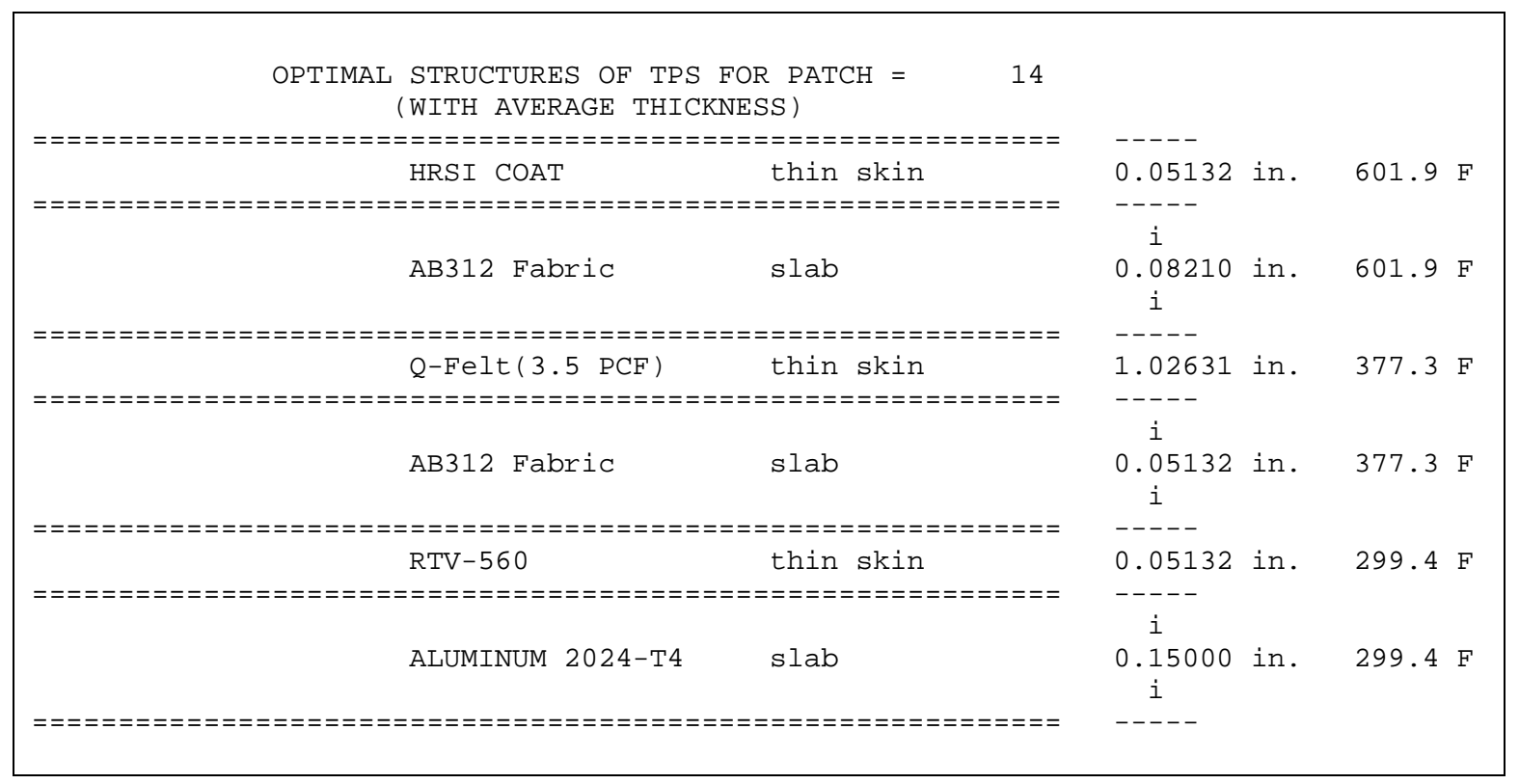

Figure 30. TPS - (B) for Fuselage and Wing Surface -final (Based on X1004701 Trajectory/Flight Conditions) 


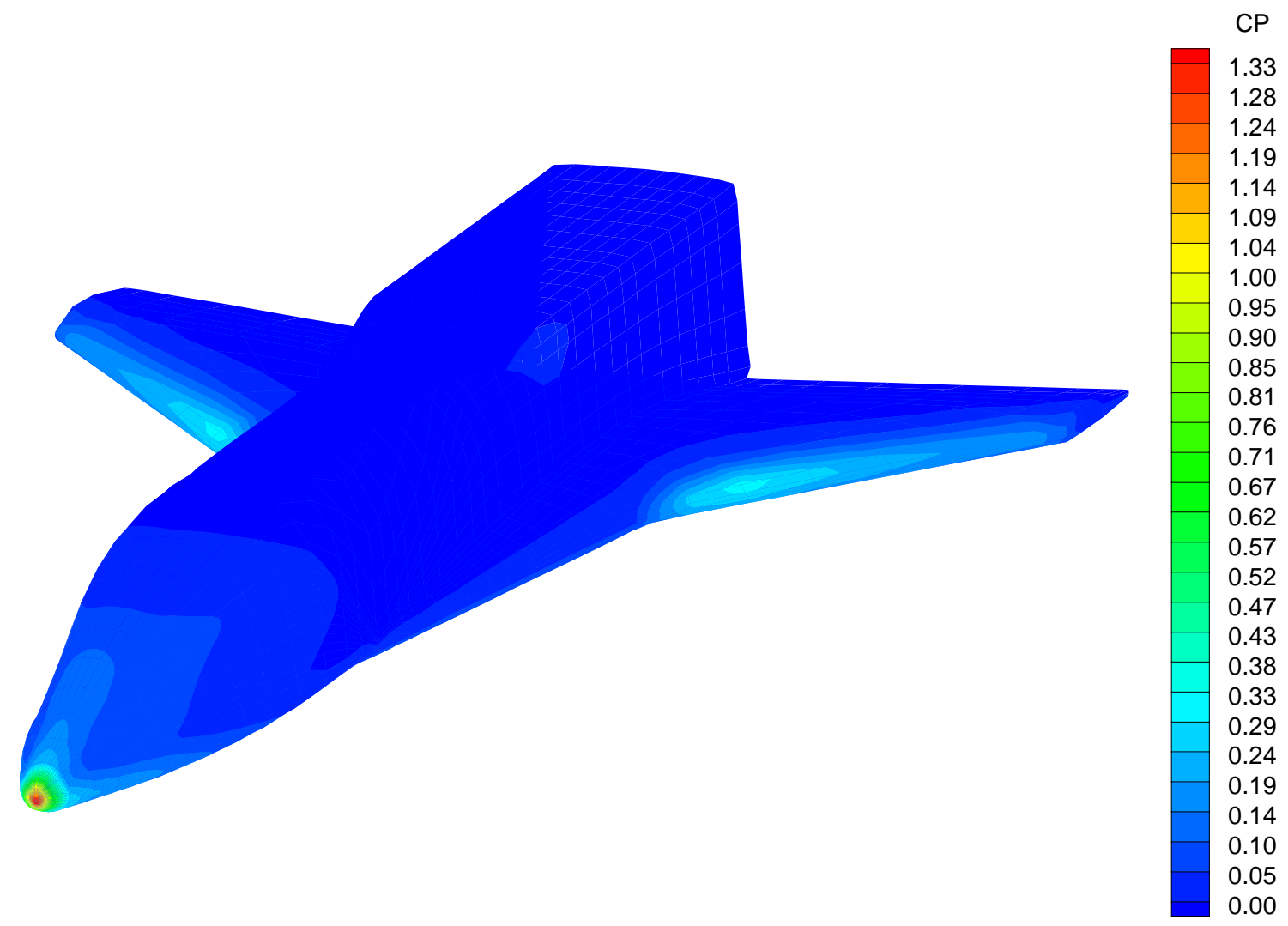

Figure 31. Cp at time $=225$ seconds with $\mathrm{M}=8.8, \mathrm{AoA}=10.225$

(Based on X1004701 Trajectory/Flight Conditions)

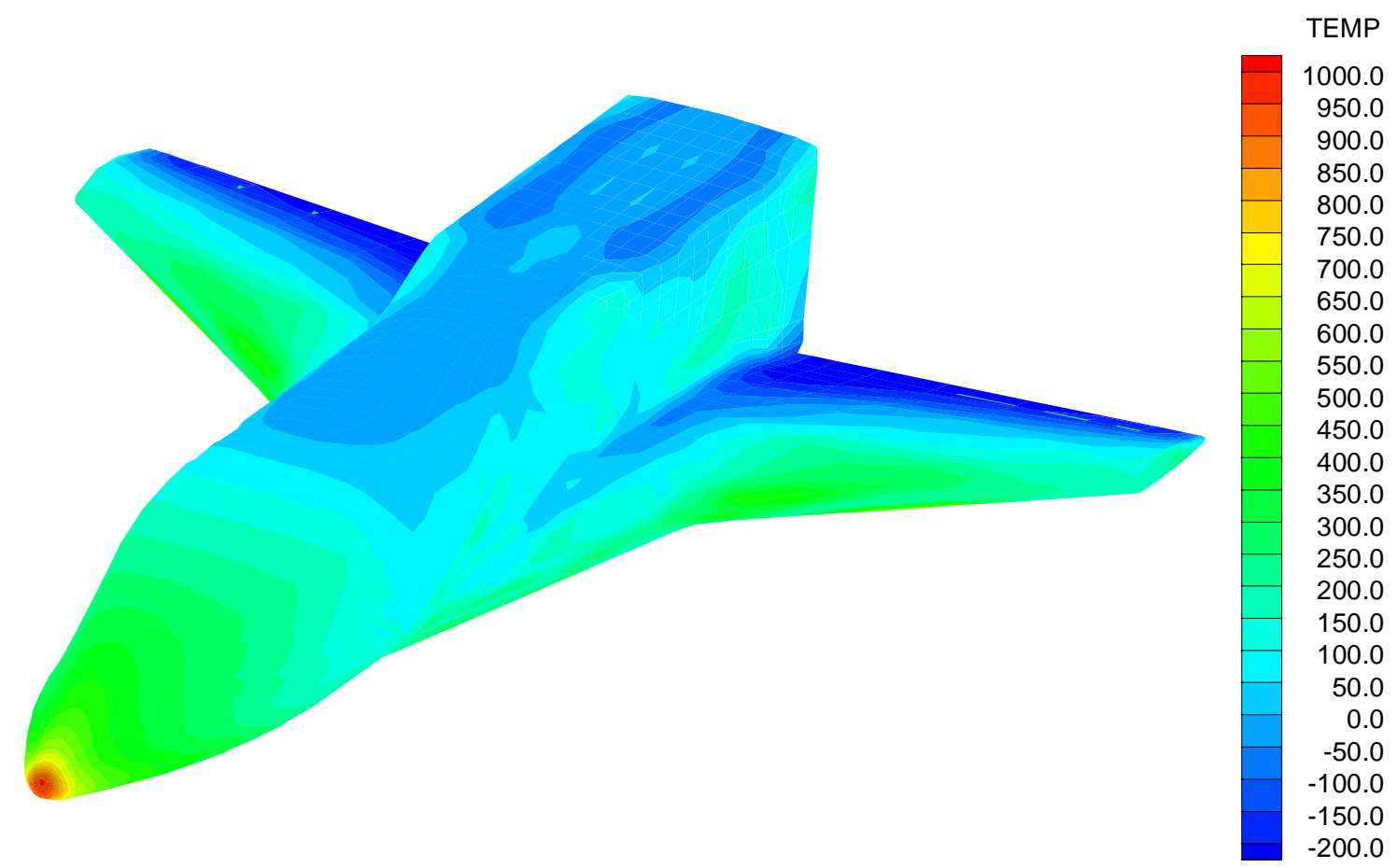

Figure 32. Temperature at time $=225$ seconds with $M=8.8, A 0 A=10.225$ (Based on X1004701 Trajectory/Flight Conditions) 


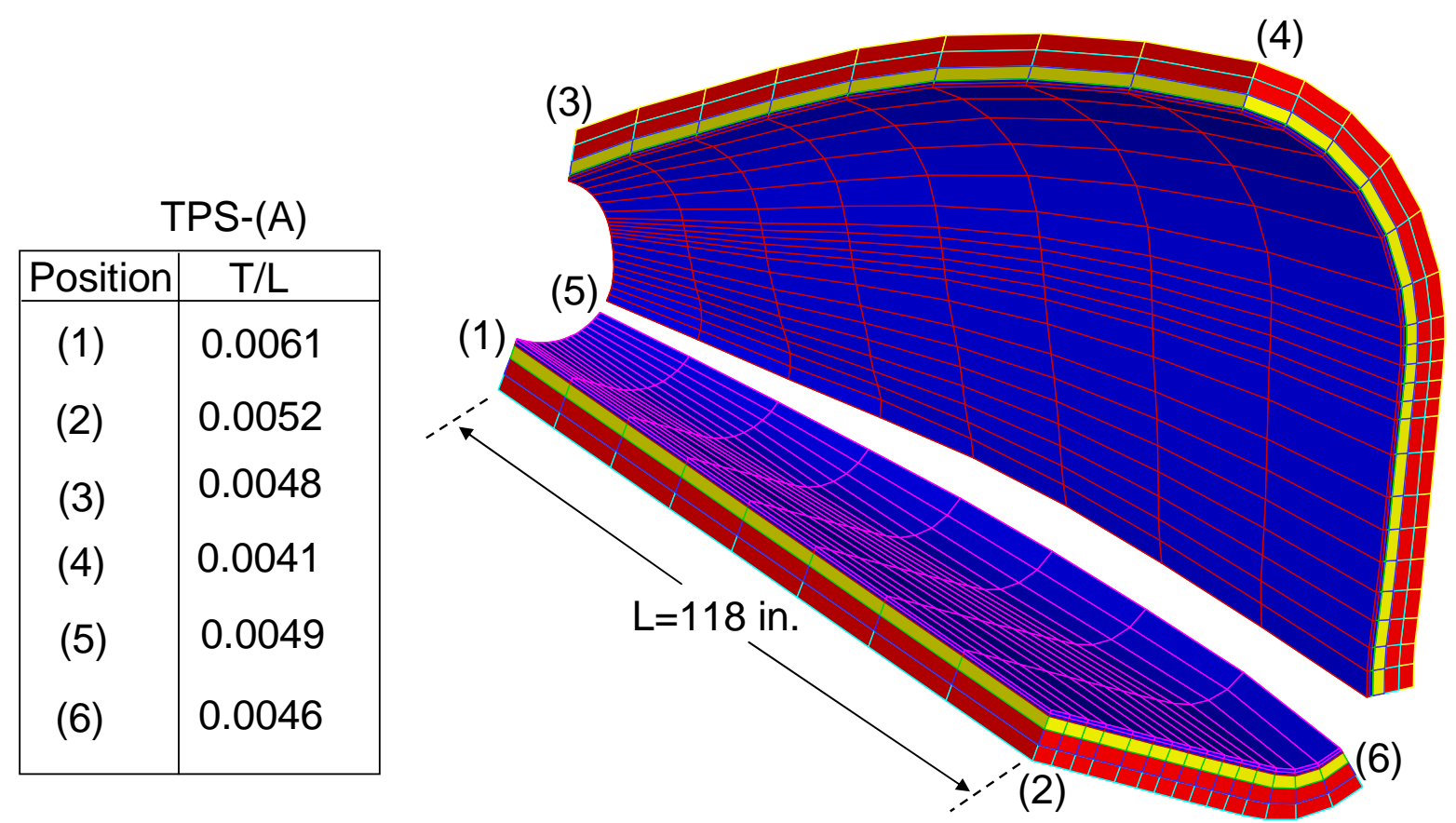

Figure 33. Optimal Thickness for Patches 1 and 2

(Based on X1004701 Trajectory/Flight Conditions)

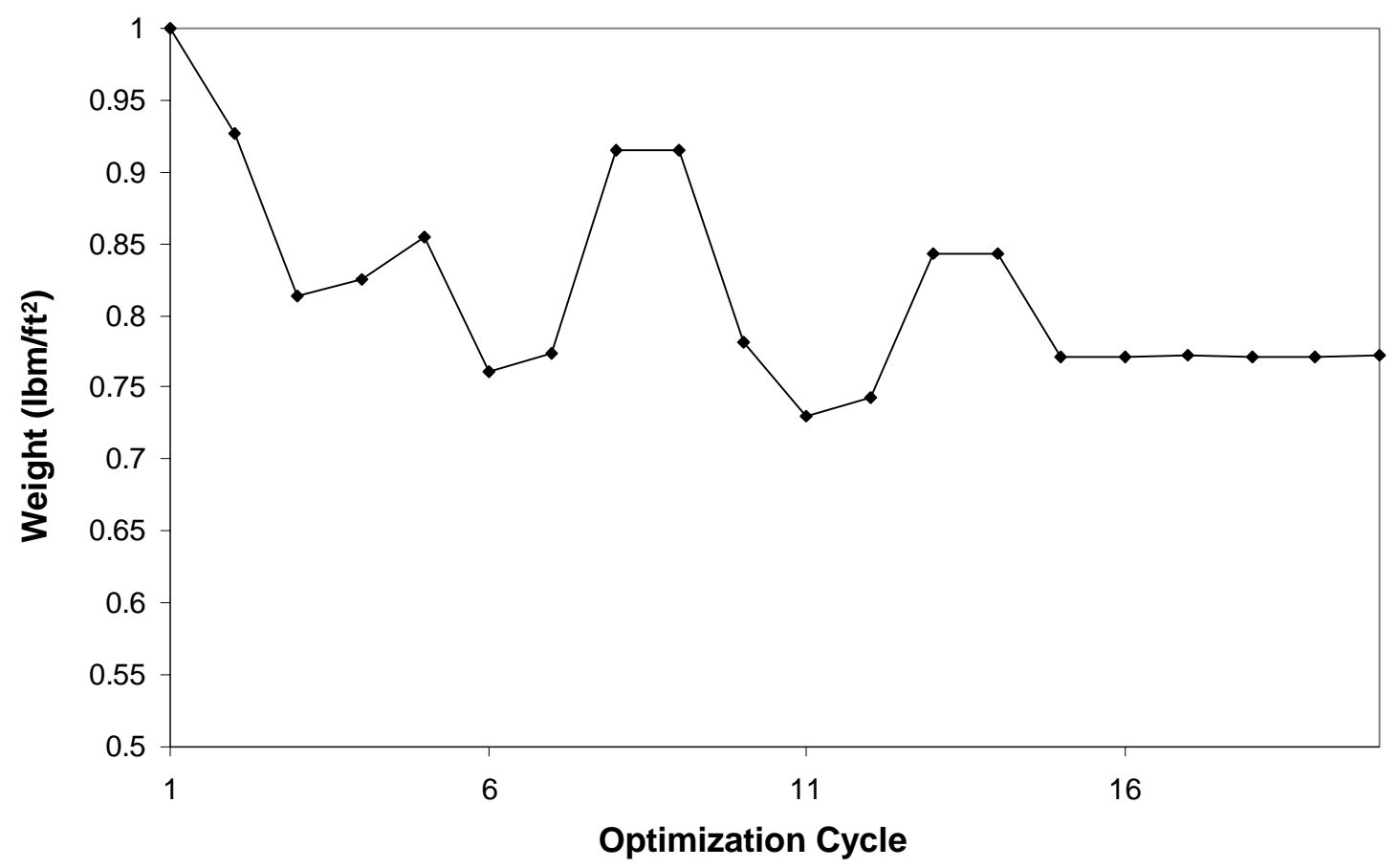

Figure 34. Iteration History of the Objective Function during Optimization Process of TPSOPT X1004701, Trajectory and Flight Condition History 


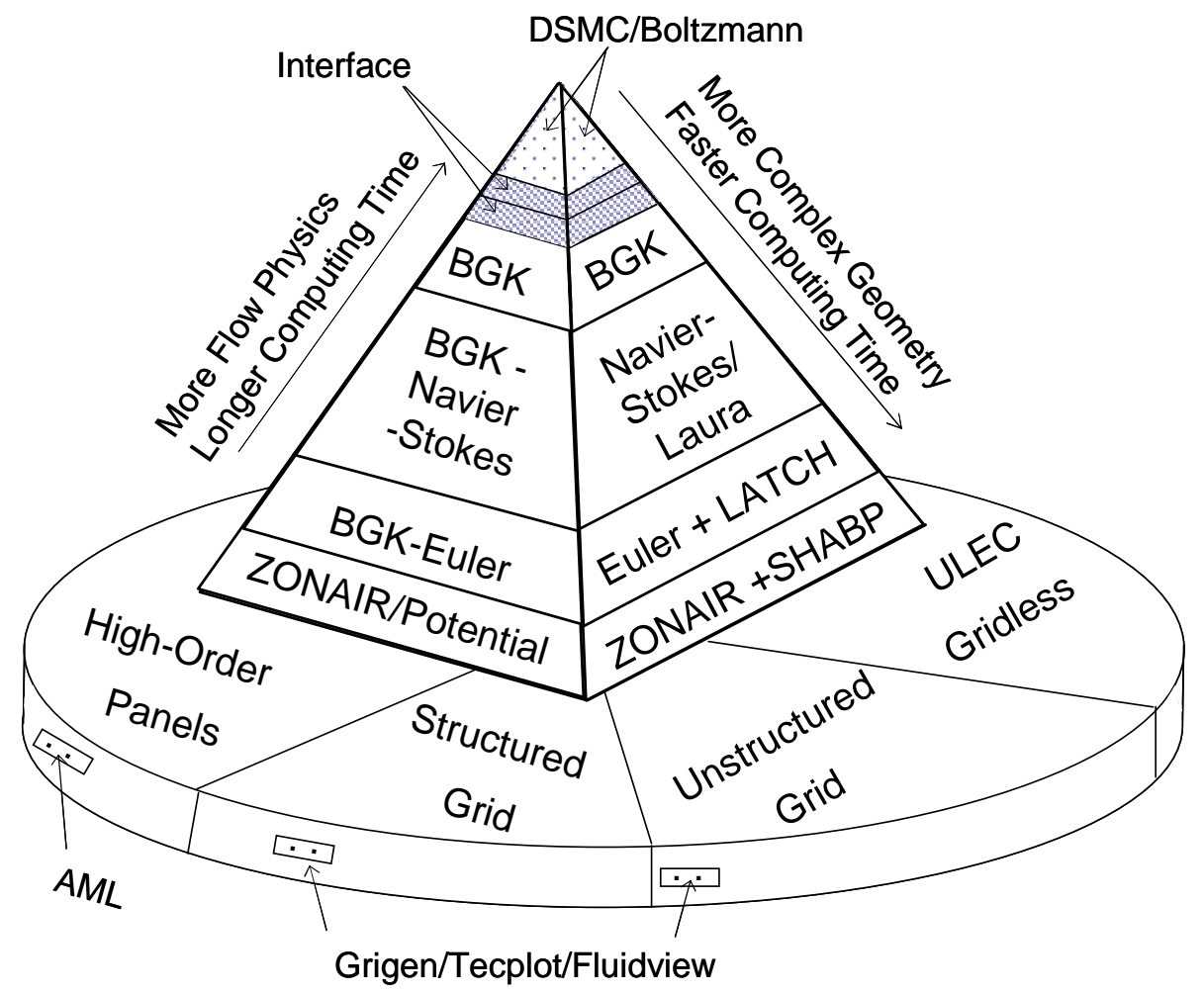

Figure 35. Computational Aerodynamic/Aerothermodynamic Software Toolbox (CAAST) 